\title{
Boosting Lattice Oxygen Oxidation of Perovskite to Efficiently Catalyze Oxygen Evolution Reaction by FeOOH Decoration
}

\author{
Jia-Wei Zhao, Cheng-Fei Li, Zi-Xiao Shi, Jie-Lun Guan, and Gao-Ren Li (i) \\ MOE Laboratory of Bioinorganic and Synthetic Chemistry, The Key Lab of Low-Carbon Chemistry \& Energy Conservation of \\ Guangdong Province, School of Chemistry, Sun Yat-sen University, Guangzhou 510275, China \\ Correspondence should be addressed to Gao-Ren Li; ligaoren@mail.sysu.edu.cn
}

Received 23 March 2020; Accepted 31 May 2020; Published 10 July 2020

Copyright (C) 2020 Jia-Wei Zhao et al. Exclusive Licensee Science and Technology Review Publishing House. Distributed under a Creative Commons Attribution License (CC BY 4.0).

In the process of oxygen evolution reaction (OER) on perovskite, it is of great significance to accelerate the hindered lattice oxygen oxidation process to promote the slow kinetics of water oxidation. In this paper, a facile surface modification strategy of nanometerscale iron oxyhydroxide (FeOOH) clusters depositing on the surface of $\mathrm{LaNiO}_{3}$ (LNO) perovskite is reported, and it can obviously promote hydroxyl adsorption and weaken Ni-O bond of LNO. The above relevant evidences are well demonstrated by the experimental results and DFT calculations. The excellent hydroxyl adsorption ability of $\mathrm{FeOOH}-\mathrm{LaNiO}_{3}$ (Fe- $\mathrm{LNO}$ ) can obviously optimize $\mathrm{OH}^{-}$filling barriers to promote lattice oxygen-participated OER (LOER), and the weakened Ni-O bond of LNO perovskite can obviously reduce the reaction barrier of the lattice oxygen participation mechanism (LOM). Based on the above synergistic catalysis effect, the Fe-LNO catalyst exhibits a maximum factor of 5 catalytic activity increases for OER relative to the pristine perovskite and demonstrates the fast reaction kinetics (low Tafel slope of $42 \mathrm{mV} \mathrm{dec}^{-1}$ ) and superior intrinsic activity (TOFs of $\sim 40 \mathrm{O}_{2} \mathrm{~S}^{-1}$ at $1.60 \mathrm{~V}$ vs. RHE).

\section{Introduction}

Oxygen evolution reaction (OER) as a half reaction of overall water splitting is important for many energy storage applications such as solar cells, metal-air batteries, and fuel cell [13]. However, its sluggish kinetics with multistep protoncoupled electron transfer and high overpotential frustrate its commercial applications. Though the state-of-the-art precious metal oxides such as $\mathrm{IrO}_{2}$ or $\mathrm{RuO}_{2}$ demonstrate the most active OER catalysts, they suffer significantly from high cost and instability in the practical applications [4]. In recent studies, emerging as a family of outstanding alternatives, crystalline or amorphous transitional metal oxides and metal oxyhydroxides have been widely exploited because of their high catalytic activity, low cost, and environmentally benign character [5]. Among them, low-cost perovskite with $\mathrm{ABO}_{3}$ formula ( $\mathrm{A}$ is a rare-earth or alkaline-earth element and $\mathrm{B}$ is a transition metal) has drawn particular attention due to its structural adjustability and high intrinsic performance [6-8]. For example, Suntivich et al. proposed a structural regulation method to optimize the OER activity of perovskite by tailoring the $\mathrm{e}_{\mathrm{g}}$ filling electrons of $\mathrm{B}$ site transition metal [9].
Grimaud et al. reported that the OER catalytic performance of double perovskites is greatly related to the lattice oxygen $2 p$ band center [10]. Despite the fact that much progress has been made on establishing related theory to explain the OER activity of perovskites, there are still some challenging facts including (1) explanation of the nonconcerted protonelectron transfer (NCPET) process of some perovskites during OER, which exhibits pH-dependent catalytic activity on the RHE scale; (2) the surface structural change with A site leaching during OER; and (3) the OER performance related to the $\mathrm{O}$ vacancies and $\mathrm{O} 2 \mathrm{p}$ band center in perovskite. Therefore, it is highly urgent to propose an effective theory to comprehensively understand the OER mechanism of perovskite.

With further studies of perovskite in recent years, it has been found that the mechanism of the NCPET process and surface structural change of perovskite are attributed to the lattice oxygen-participated OER (LOER), which was first observed by in situ ${ }^{18} \mathrm{O}$ isotope labeling with mass spectrometry [11]. Additionally, numerous studies have indicated that the unusual reaction pathway of the lattice oxygen participation mechanism (LOM) has a faster OER kinetics and lower 
reaction energy barriers compared with adsorbate evolution mechanism (AEM) [12-14], because of bypassing the theoretical overpotential limitation of $0.37 \mathrm{~V}$ [15]. Therefore, the study of LOER is of great significance for perovskites. To the best of our knowledge, one of the most direct ways to active LOER of perovskite is replacing the alkaline-earth metal A site to regulate the strength of metal-oxygen bond [11]. For example, Mefford et al. found that $\mathrm{LaCoO}_{3-\delta}$ underwent LOER via $\mathrm{Sr}$ doping $(\mathrm{Sr}>50 \%)$ [16], which showed excellent OER performance. However, this method is not applicable to other perovskites such as $\mathrm{LaNiO}_{3-\delta}$, which lead to structural transformation and performance degradation after Sr doping [17]. Therefore, to overcome this shortcoming, a new method should be proposed to boost the LOER of perovskite without changing the original structure of catalysts.

With this intention, we focus on the key step of LOM based on our previous studies [18-35], a $\mathrm{OH}^{-}$filling pathway, as shown in the following formulas $\left\{\left[\mathrm{O}=\mathrm{O}-\mathrm{MO}_{4}\right] \rightarrow\left[\mathrm{V}-\mathrm{MO}_{4}\right]+e^{-}\right\}$and $\left\{\left[\mathrm{V}-\mathrm{MO}_{4}\right]+\mathrm{OH}^{-} \rightarrow\left[\mathrm{HO}_{\text {ads }}-\mathrm{MO}_{4}\right]+e^{-}\right.$ \}, where $\mathrm{M},\left[\mathrm{MO}_{4}\right]$, and $\mathrm{V}$ denote the transition metal $\mathrm{B}$ site of perovskite, the surface structure with oxygen vacancies, and $\mathrm{O}$ vacancy, respectively. Some studies have demonstrated that $\mathrm{OH}^{-}$filling is thermodynamically favorable in some perovskite and plays a key role in LOER [36]. However, the $\mathrm{OH}^{-}$filling is much slower than leaching of lattice oxygen [37], which restricts the performance and even causes intensive surface structural change during OER [38]. Therefore, accelerating the lattice oxygen participation process of perovskite and promoting hydroxyl adsorption will be a direct and efficient method to enhance the catalytic performance of perovskite, but this method is almost a blank field to date. Based on this assumption, we present a facile surface modification strategy to directly optimize the hydroxyl adsorption step on oxygen vacancy of B site of perovskite to accelerate the lattice oxygen participation process by depositing $\mathrm{FeOOH}$ nanoclusters on the surface of $\mathrm{LaNiO}_{3}(\mathrm{LNO})$ perovskite (a representative semimetallic perovskite). As we all know, metal oxyhydroxides own high hydroxyl adsorption capacity [39-41]. Furthermore, the electronic effect between metal oxyhydroxide and metal oxide will change the chemical environments of the interfaces [42]. The excellent hydroxyl adsorption ability of $\mathrm{FeOOH}-\mathrm{LaNiO}_{3}$ (Fe-LNO) can obviously accelerate LOER, while the strong electronic interaction between $\mathrm{FeOOH}$ and $\mathrm{LNO}$ perovskite can lead to positive shifting of the $\mathrm{O} 2 \mathrm{p}$ band center and negative shifting of the $\mathrm{Ni}$ $3 \mathrm{~d}$ center of LNO, which will obviously reduce the reaction barrier of LOM. The above advantages make Fe-LNO own high catalytic performance for OER, which is comparable to that of state-of-the-art Ni-Fe (oxy)hydroxide amorphous catalysts. This work provides a novel strategy to optimize and study the LOER of perovskites.

\section{Results and Discussion}

2.1. Fe-LNO Catalyst Synthesis and Characterizations. The heterostructured Fe-LNO was synthesized by a simple deposition way. Firstly, polycrystalline $\mathrm{LaNiO}_{3}$ (LNO) powders were synthesized from a mixture of metal nitrate (La and $\mathrm{Ni}$ ) and citric acid through the Pechini method. Secondly, the obtained LNO powders were dispersed in $\mathrm{Fe}^{2+}$ solution of low concentration, and the $\mathrm{pH}$ of the solution was kept around 4 to prevent LNO from etching (Figure S1) [43]. After deposition of FeOOH for $5 \mathrm{~min}$, the Fe-LNO sample was obtained by centrifuging the above solution three times. Fundamental characterizations of LNO and Fe-LNO by scanning electron microscopy (SEM) and powder X-ray diffraction (PXRD) were performed. The samples LNO and Fe-LNO both exhibit the nanoparticle assemble morphology with a similar size distribution in the range of 100 to $150 \mathrm{~nm}$ as shown in Figures S2 and S3. In addition, the Rietveld refined XRD patterns in Figures S8 and S9 indicate the rhombohedral structure (space group: $\mathrm{R} \overline{3} \mathrm{c}$ ) of LNO with a lattice constant of $a=b=5.457 \AA, c=13.180 \AA$, and there is no extra peak for the Fe-LNO sample, which shows that $\mathrm{FeOOH}$ is amorphous. Furthermore, the structure of $\mathrm{FeOOH}$ nanoclusters was confirmed by Raman spectra and high-resolution X-ray photoelectron spectroscopy (XPS) spectra (Figures S10b and S14b). The Raman peaks at around $560 \mathrm{~cm}^{-1}$ are ascribed to the typical $\alpha$-FeOOH structure [44], and the XPS peak of Fe $2 p$ also confirmed the existence of $\mathrm{FeOOH}$ [45]. To characterize the contact state of Fe-LNO two phases, the transmission electron microscopy (TEM) images of LNO and Fe-LNO are shown in Figures $1(\mathrm{~b})$ and $1(\mathrm{c})$, which show that the pristine LNO has a smooth surface, while $\mathrm{FeOOH}$ nanoparticles with $\sim 10 \mathrm{~nm}$ are discontinuously distributed on the LNO surface. A high density of heterointerfaces of $\mathrm{FeOOH} / \mathrm{LNO}$ is obtained. To further confirm the compositions of two phases, highresolution TEM (HRTEM) images are shown in Figure 1(d), which shows that the structure of inner LNO is crystalline, while $\mathrm{FeOOH}$ nanoparticles are amorphous (Figure 1(e)). The heterointerfaces of $\mathrm{FeOOH} / \mathrm{LNO}$ can be further confirmed by fast Fourier transform (FFT) as shown in Figures $1(\mathrm{f})$ and $1(\mathrm{~g})$, which also indicates polycrystalline LNO and amorphous $\mathrm{FeOOH}$ nanoparticles, respectively.

Given the unique structure of Fe-LNO and the synergistic effect of heterointerface, we propose the synergetic catalysis mechanism to regulate LOER as schematically illustrated in Figure 1(a). The LNO is the main catalysis site, and the $\mathrm{FeOOH}$ nanoclusters served as a cocatalyst for promoting hydroxyl adsorption. Beyond that, under the synergistic effect of heterointerface, the $\mathrm{FeOOH}$ nanoclusters can weaken the Ni-O bond in LNO to facilitate the formation of $\mathrm{O}_{\mathrm{NB}}$, which is preferred to be oxidized during water oxidation and will reduce the energy barrier of LOER [15].

\subsection{Theoretical Study of LOM Promoted by $\mathrm{FeOOH}$. As we all} know, the semimetallic Ni-based crystalline oxide $\mathrm{LaNiO}_{3}$ (LNO) exhibiting high OER activity mainly arises from the structure and molecular orbital of LNO [13]. Namely, the $\mathrm{Ni}$ cations are in the low spin state with fully occupied $t_{2 g}$ states (Figures S15-S17), and the $\mathrm{e}_{\mathrm{g}}$ orbit of $\mathrm{Ni}^{29}$ participates in $\sigma$-bonding with the surface-anion adsorbate, accompanied with the single electron and high energy of $e_{g}$ orbit promoting OER catalytic activity [9]. However, according to recent studies, the high OER catalytic activity of LNO is caused by the lattice oxygen redox reaction [12, $36]$. When the $\mathrm{O} 2 \mathrm{p}$ state at the LNO Fermi level lies above 


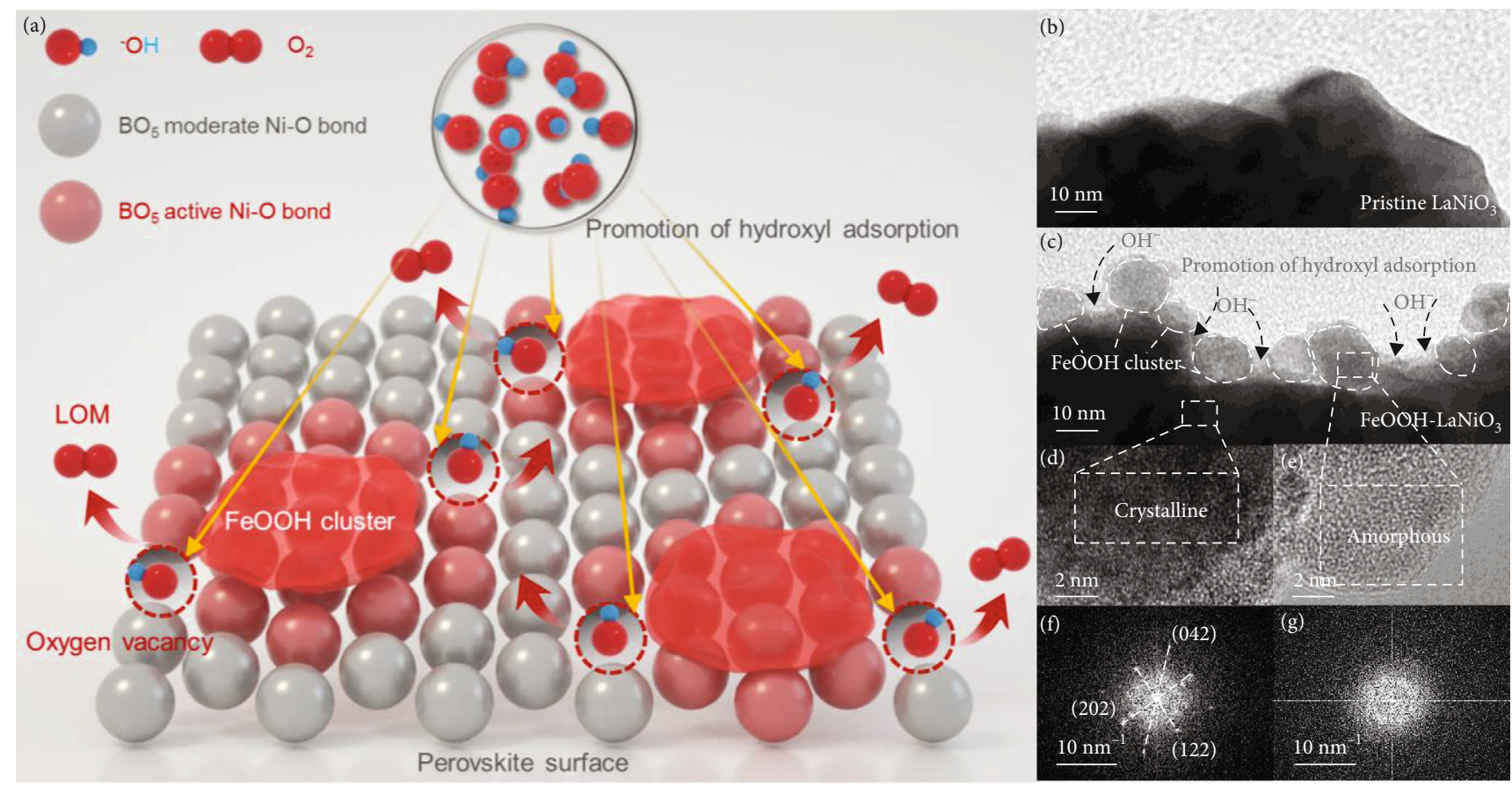

FIGURE 1: Catalyst synthesis and characterizations. (a) The illustration of synergetic catalysis mechanism of Fe-LNO. (b, c) TEM image of pristine LNO and Fe-LNO. (d, e) HRTEM images of LNO and Fe-LNO. (f, g) The corresponding FFT images of LNO and Fe-LNO.

the oxidation energy of $\mathrm{H}_{2} \mathrm{O}$, the LOM step in the perovskites becomes thermodynamically favorable (Figure 2(d)) [46]. Therefore, according to the above-mentioned methods, the studies are mainly focused on the LOM and AEM [11]. The main difference between LOM and AEM lies in the coordination mode of hydroxyl groups: AEM is the top of the B site (Figure 2(b)), while LOM is the top of the B site near the oxygen vacancy (Figure 2(c)). In addition, during the AEM process, transition metal oxides are often limited by the second step of OER for the large $\mathrm{O} *$ formation energy $\left(G_{O *}\right)[47,48]$ while the barrier of LOM is the hydroxyl adsorption step $\left(\mathrm{G}_{\mathrm{OH} *}\right)$ [12]. Therefore, we further simulate different mechanisms of LNO by the density functional theory (DFT) calculations as shown in Figures 2(e) and 2(f), and the related reaction structures are listed in Figures S21 and S22. The OER pathway free energy of 4-coordinated $\mathrm{Ni}$ is always lower than that of 5coordinated $\mathrm{Ni}$ except the hydroxyl adsorption step, which can be attributed to the decrease of $\mathrm{dz}^{2}$ energy [49] and the easier formation of $\mathrm{Ni}-\mathrm{O}$ bond during OER, resulting to the fact that the theoretical overpotential of LOM is much lower than that of AEM. However, the actual operation activity of LNO is much lower than the predicted results $[50,51]$, and this can be mainly ascribed to two reasons: (1) the barrier of hydroxyl adsorption and (2) the stable Ni-O bond that obstructs the formation of the $\mathrm{O}_{\mathrm{NB}}$ state. In order to address the above questions, we first study the electronic effect between $\mathrm{FeOOH}$ and LNO by the first principle DFT calculations. The typical model of Fe-LNO is shown in Figures $2(\mathrm{~g})$ and $2(\mathrm{~h})$ and Figure S26. As the structure of $\mathrm{FeOOH}$ nanoclusters is too large for a plane wave-based periodicity DFT simulations [52], the interaction between two catalysts is constructed by supercell matching [53]. The lattice mismatching error is less than $8 \%$, and the whole structure is completely relaxed to ensure no additional lattice stress. In order to compare the electronic effects between two phases, $\mathrm{NiO}_{5}$ in the adjacent $\mathrm{FeOOH}$ layer is marked as the surface layer, and the $\mathrm{NiO}_{5}$ in the interior is marked as bulk. Based on the above model, the synergistic effects between $\mathrm{FeOOH}$ and LNO are studied in Figure 2(i). It is evident that the $G$ $(* \mathrm{OH}) \quad$ value $(0.28 \mathrm{eV})$ of $\mathrm{Fe}-\mathrm{LNO}$ catalyst is significantly lower than that of LNO $(1.07 \mathrm{eV})$, suggesting that the $\mathrm{FeOOH}$ can facilitate hydroxyl adsorption on the surface of LNO, which is consistent with the differential charge transfer analysis as shown in Figure S28. Ni 3d electron pairs induced by $\mathrm{FeOOH}$ make the hydroxyl coordination more stable and thus shorten $\mathrm{Ni}-\mathrm{OH}$ bond from $2.022 \AA$ to $1.911 \AA$. Furthermore, the calculated projected density of states (PDOS) of surface $\mathrm{NiO}_{5}$ and bulk $\mathrm{NiO}_{5}$ has been conducted as shown in Figures 2(j) and 2(k). Both of the centers of $\mathrm{Ni} 3 \mathrm{~d}$ band and $\mathrm{O} 2 \mathrm{p}$ band shift positively, making the lattice oxygen closer to the Fermi level. The lattice $\mathrm{O}$ in $\mathrm{NiO}_{5}$ will become more favorable to be oxidized during OER, and the surface $\mathrm{Ni}$ will become more easy to coordinate with $* \mathrm{OH}$. These results demonstrate that the $\mathrm{FeOOH}$ can optimize $\mathrm{OH}^{-}$filling barriers and weaken Ni-O bond of LNO to decrease the energy barrier of LOM and promote reaction kinetics.

2.3. The Evidences of Hydroxyl Adsorption Promoted by $\mathrm{FeOOH}$. The leaching of A site, resulting in mass loss of La in LNO, is a universal phenomenon during the LOER. This phenomenon is due to the lower barrier of hydroxyl adsorption than that of lattice oxygen leaching $[4,37,54]$, as shown in Figure 3(a). Therefore, this phenomenon will be 


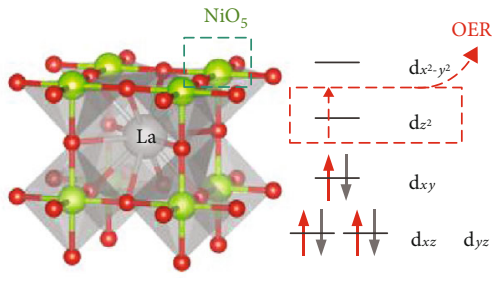

(a)

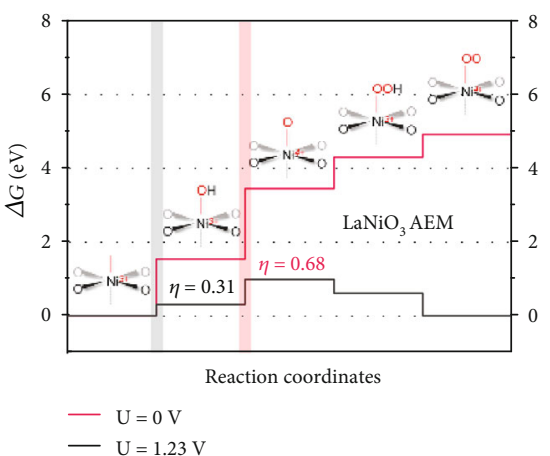

(e)

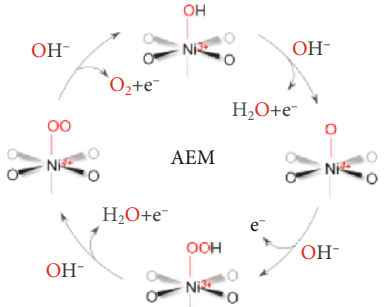

(b)

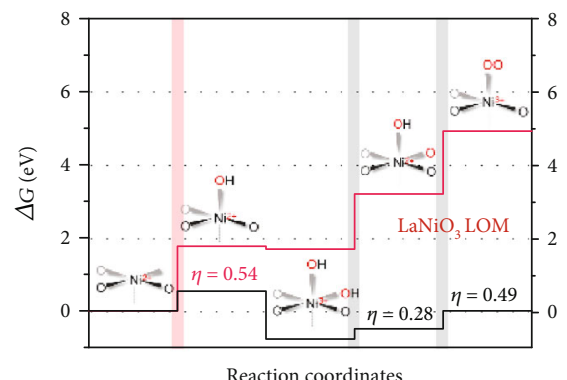

- $\mathrm{U}=0 \mathrm{~V}$

- $\mathrm{U}=1.23 \mathrm{~V}$

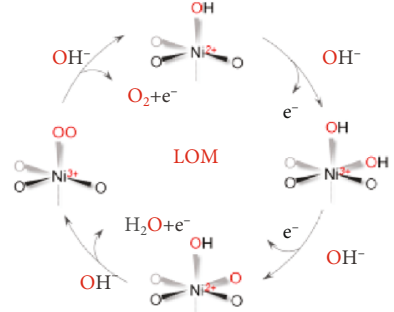

(c)

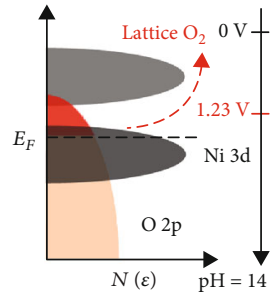

(d)

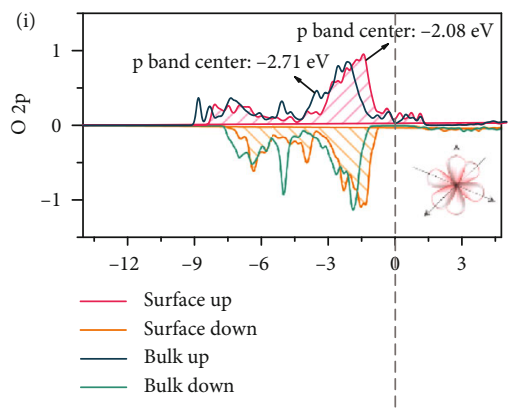

(f)

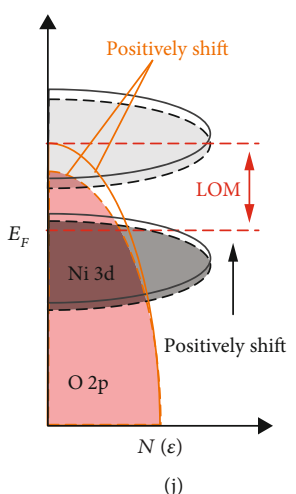

(ii)
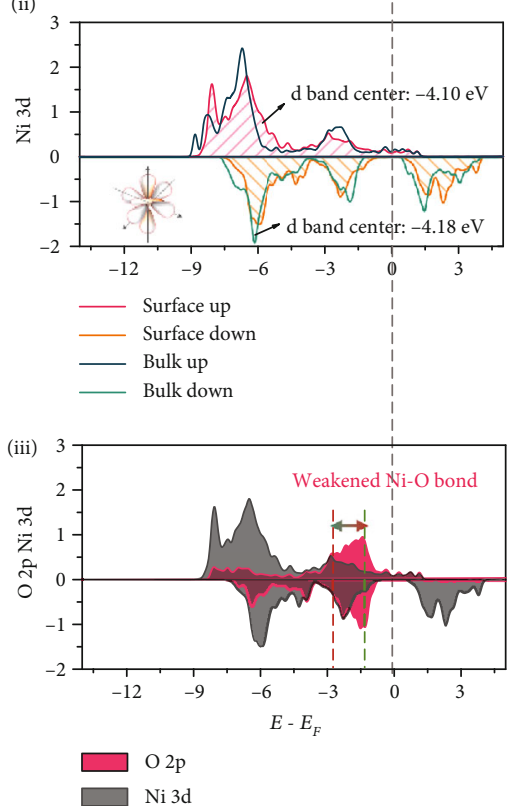

(k)

FIgure 2: Theoretical studies of LOM and AEM of Fe-LNO. (a) The $\mathrm{ABO}_{3}$ structures with chemical reaction surface [BO 5 ]. (b, c) The proposed OER mechanisms of LNO, including AEM and LOM. (d) Schematic rigid band diagrams of LNO. The position of the $\mathrm{O}_{2} / \mathrm{H}_{2} \mathrm{O}$ redox couple at $\mathrm{pH} 14$ is $1.23 \mathrm{~V}$ versus RHE. (e, f) Free energies of OER steps via AEM and LOM mechanisms on LNO. (g, h) The constructed model of Fe-LNO heterostructure. (i) The hydroxl adsorption energy of LNO and Fe-LNO. (j) LOM mechanism optimized by FeOOH. (k) pDOS of $\mathrm{O}(2 \mathrm{p})$ and $\mathrm{Ni}(3 \mathrm{~d})$ orbitals in the surface $\mathrm{NiO}_{5}$ and bulk $\mathrm{NiO}_{5}$.

significantly weakened with the acceleration of hydroxyl adsorption by $\mathrm{FeOOH}$. In order to prove the hydroxyl adsorption mechanism, the time-dependent test was carried out with an inductively coupled plasma-mass spectrometer (ICP-MS) and inductively coupled plasma-atomic emission spectrometry (ICP-AES) as shown in Figure 3(b). We detected the La concentration in the electrolyte at different chronopotentiometric times. The amount of La leached from the LNO sample is $14.3 \mathrm{ng} \mathrm{ml}^{-1}$ (ICP-MS) and $12.5 \mathrm{ng} \mathrm{m}^{-1}$ (ICP-AES), while the amount of La leached from the Fe-
LNO sample is $0.98 \mathrm{ng} \mathrm{ml}^{-1}$ (ICP-MS) and $0 \mathrm{ng} \mathrm{ml}^{-1}$ (ICPAES), indicating that the $\mathrm{FeOOH}$ can effectively alleviate the leaching of La. This result well proves the promotion of hydroxyl adsorption. To further demonstrate that $\mathrm{FeOOH}$ can promote the hydroxyl adsorption of LNO, we also used a simple $\mathrm{pH}$ test to measure the change of $\mathrm{pH}$ in the supernatant by dispersing the material evenly in the same solution, and then, we calculated the hydroxyl adsorption of catalyst (Figure 3(c)). The Fe-LNO exhibits the highest hydroxyl adsorption capacity nearly $1: 1$, and the hydroxyl adsorption 

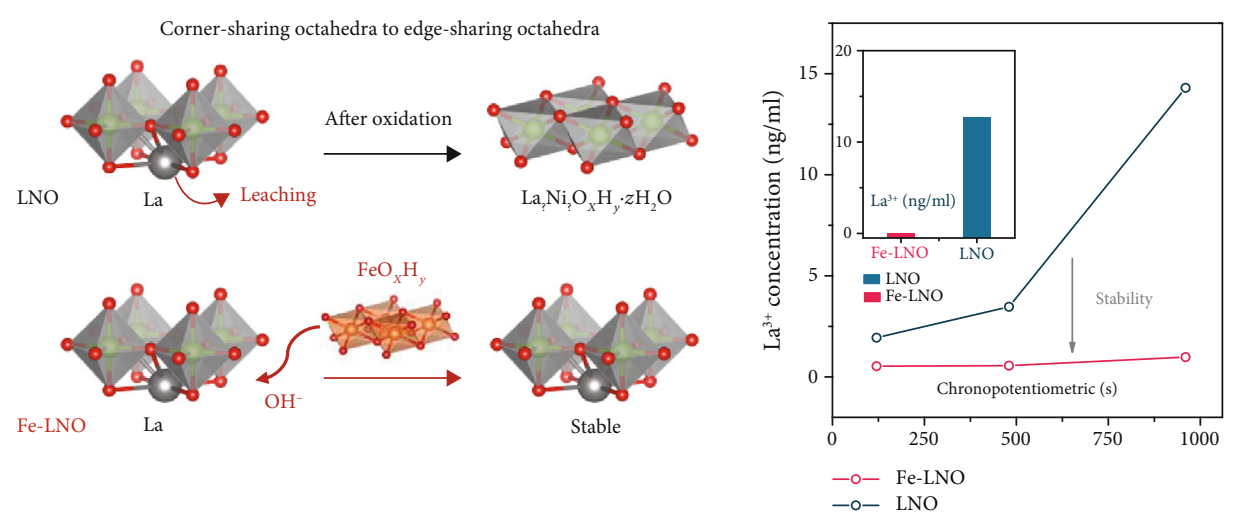

(b)

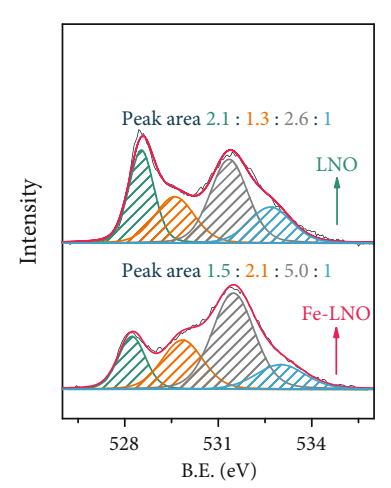

VIJ $\mathrm{O}^{2-} \quad \mathrm{VIC} \mathrm{O}_{2}$ or ${ }^{-} \mathrm{OH}$ VIJ $\mathrm{O}^{2-2 / \mathrm{O}^{-}} \mathrm{VIJ} \mathrm{H}_{2} \mathrm{O}$ (a)

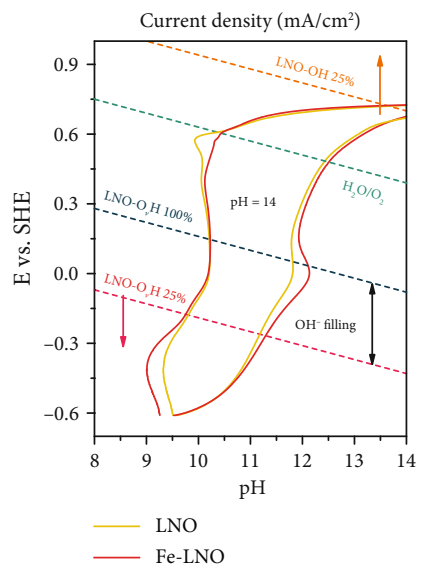

(d)

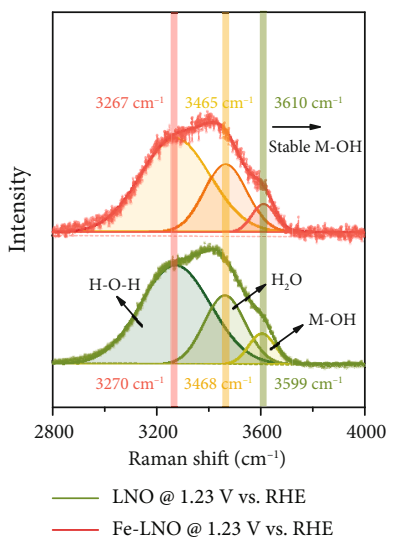

(f)

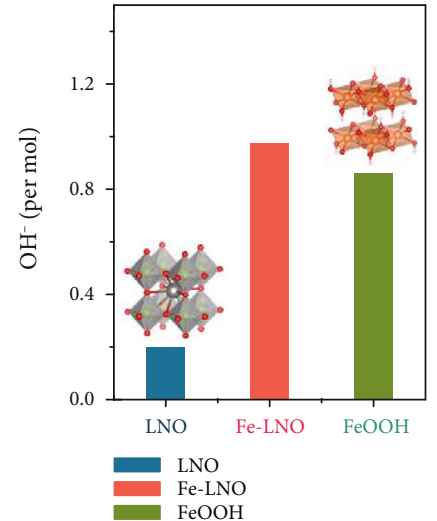

(c)

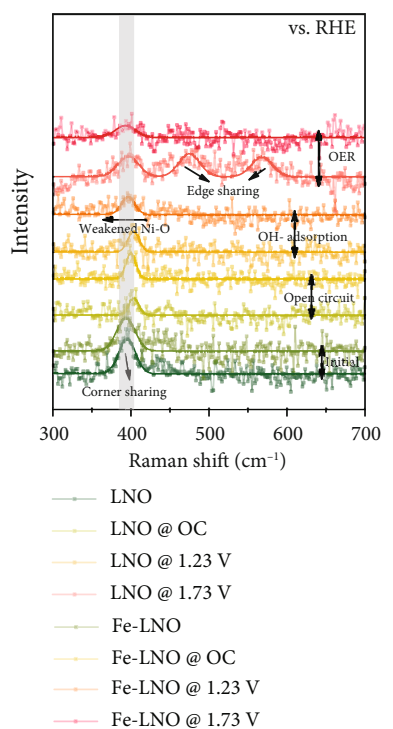

(g)

FIgURE 3: Evidence of hydroxyl adsorption promotion by FeOOH. (a) Illustration of the mechanism of hydroxyl adsorption with structure change. (b) Time-dependent ICP-MS and ICP-AES of LNO and Fe-LNO; test with chronopotentiometry holds at $10 \mathrm{~mA} / \mathrm{cm}^{2}$. (c) Hydroxyl adsorption experiment by pH study. (d) O 2p XPS spectra of the Fe-LNO and LNO. (e) Cyclic voltammograms and hydroxyl adsorption voltage ranges by DFT calculations; the solid line represents the cyclic voltammograms of samples, and the dashed line is the prediction voltage ranges. (f) In situ Raman spectra of Fe-LNO and LNO at $1.23 \mathrm{~V}$ vs. RHE. (g) In situ Raman spectra of Fe-LNO and LNO in different voltages.

capacity of Fe-LNO is even better than that of pure $\mathrm{FeOOH}$, which is much larger than that of LNO $(0.2: 1)$, indicating that the modification of $\mathrm{FeOOH}$ can greatly optimize the adsorption of hydroxyl. To further determine whether the adsorbents are chemisorption of $* \mathrm{OH}$ or physisorption of hydroxyl, XPS was used to further prove the adsorption state of hydroxyl [55], as shown in Figure 3(d). By comparing the area ratio of the hydroxyl peak and water peak of Fe-LNO and LNO, we found that the adsorption of hydroxyl by FeLNO was significantly improved in the range of $2.6: 1$ to $5.0: 1$, implying the generation of a high density of extra oxygen vacancies filled by hydroxyl. We also compared the hydroxyl peak ratio of pure $\mathrm{FeOOH}$ in Figure S14a, which is in the range of $3.5: 1$, less than that of Fe-LNO. In addition, the peak at around $529.5 \mathrm{eV}$ can be attributed to the $\mathrm{O}_{\mathrm{NB}}$ states [15], which indicates that the $\mathrm{FeOOH}$ can activate more $\mathrm{O}_{\mathrm{NB}}$ states, and this is consistent with the DFT calculation results.

Furthermore, in order to display that hydroxyl adsorption mainly occurred at the electric field, the cyclic voltammetry and in situ Raman spectroscopy were measured. Cyclic voltammetry is a powerful tool for analyzing the chemisorption and oxidation of catalysts, which are widely utilized in $\mathrm{Pt}, \mathrm{Au}, \mathrm{RuO}_{2}$, and other well-known catalysts [56-59]. In order to predict the voltage range of $\mathrm{OH}^{-}$filling, we first calculate the free energy of $* \mathrm{OH}$ adsorption in LNO with different $* \mathrm{OH}$ coverages $(25 \% \sim 100 \%)$ (Figure S29), and the result shows that the voltage range of $* \mathrm{OH}$ adsorption is $0.40 \mathrm{~V} \sim$ $0.78 \mathrm{~V}$ (vs. RHE) in $\mathrm{pH} 14$ (Figure 3(e)). In cyclic voltammetry measurement, the significant oxidation peak at around $0.83 \mathrm{~V}$ (vs. RHE) is half chemisorption of $* \mathrm{OH}$ in a previous study [59]; thus, we marked this as the 


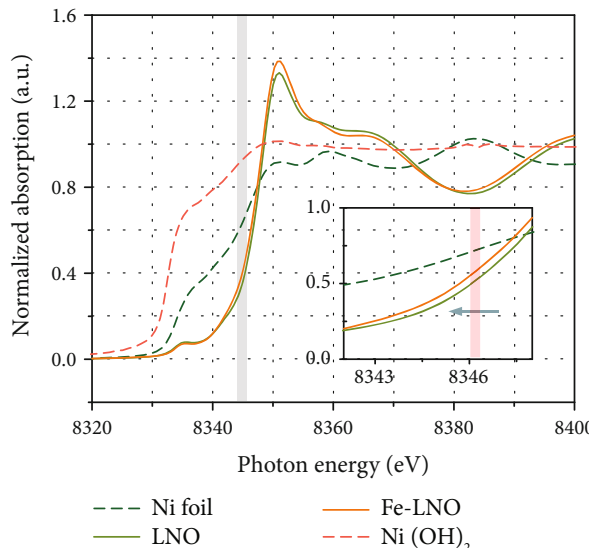

(a)

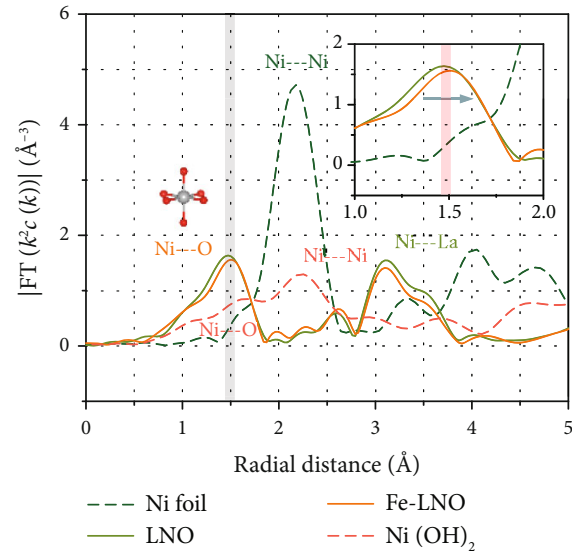

(b)
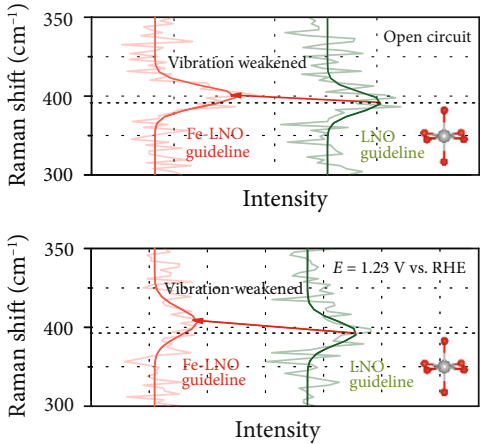

(c)

FIgURE 4: Evidences of weakened Ni-O bond. (a) Normalized nickel K-edge XANES spectra. (b) EXAFS $k^{2} \chi(k)$ Fourier transform (FT) spectra of LNO and Fe-LNO with nickel foil as a reference. (c) In situ Raman spectra of Fe-LNO and LNO in open circuit and $1.23 \mathrm{~V}$ vs. RHE.

hydroxyl adsorption peak of LNO. The initial peak potential of Fe-LNO is lower than that of LNO, which proves that $\mathrm{FeOOH}$ can accelerate the adsorption of hydroxyl. Furthermore, the peak area of Fe-LNO is about two times higher than that of LNO, which also indicates the enhancement of adsorption capacity. To further prove the adsorption of hydroxyl within this voltage range, we also studied the signal of $\mathrm{M}-\mathrm{OH}$ bond during $1.23 \mathrm{~V}$ (vs. RHE) by in situ Raman spectroscopy (Figure 3(f)). The peak at around $3270 \mathrm{~cm}^{-1}$ can be attributed to the $\mathrm{O}-\mathrm{H}$ vibration peak of water, and that at $3468 \mathrm{~cm}^{-1}$ can be attributed to the $\mathrm{H}_{2} \mathrm{O}$ vibration [60]. Obviously, both of the peaks have no shift. However, compared with that of LNO, the M-OH peak of Fe-LNO shifts from $3599 \mathrm{~cm}^{-1}$ to $3610 \mathrm{~cm}^{-1}$ [6163], and the positive shift of $\mathrm{M}-\mathrm{OH}$ indicates that the vibration of $\mathrm{M}-\mathrm{OH}$ is significantly enhanced, which is conducive to hydroxyl adsorption, consistent with DFT calculations. This further confirms that $\mathrm{FeOOH}$ can significantly promote the adsorption of hydroxyl of LNO.

The in situ Raman spectra of the catalysts in low frequency during OER are shown in Figure $3(\mathrm{~g})$. For LNO, the peaks at around $470 \mathrm{~cm}^{-1}$ and $560 \mathrm{~cm}^{-1}$ are seen, and they are typical vibration peaks of $\mathrm{Ni}-\mathrm{O}$ in $\mathrm{NiOOH}$ during OER, and this result is the same as previous reports $[44,64]$. However, few of the above peaks are found in Fe-LNO, especially the peak at $570 \mathrm{~cm}^{-1}$; a significant peak of Fe-doped $\mathrm{NiOOH}$ is not seen either. The above results confirmed that the $\mathrm{FeOOH}$ can stabilize the structure of LNO by promoting hydroxyl adsorption, which is consistent with the timedependent ICP results.

2.4. The Evidences of Weakened Ni-O Bond by FeOOH. The weakened Ni-O bond in the Fe-LNO sample is demonstrated by in situ Raman spectrum and X-ray absorption finestructure spectroscopy (XAFS). As shown in Figure 4(c), the Raman peak at around $400 \mathrm{~cm}^{-1}$ is a typical $\mathrm{e}_{\mathrm{g}}$ vibration peak of LNO [65], and it can be assigned to the strength of $\mathrm{Ni}-\mathrm{O}$ bond in $\mathrm{NiO}_{5}$ octahedra. The strength of $\mathrm{Ni}-\mathrm{O}$ was increased in $\mathrm{KOH}$ solution, and this can be attributed to the anionic adsorption of the nickel layer on the surface
[66]. We find that the $e_{\mathrm{g}}$ vibration peak of Fe-LNO samples shifted negatively, especially at $1.23 \mathrm{~V}$ vs. RHE, indicating that the FeOOH can weaken Ni-O bond of LNO. Furthermore, the K-edge XANES spectrum of nickel (Figure 4(a)) shows a slight shift toward lower energy, and this suggests the reduction state of Ni in Fe-LNO [67]. The K-edge XANES spectrum of Fe in Figure S32 shows a narrowed white-line peak, suggesting higher oxidation of $\mathrm{Fe}$ and the electron transport from $\mathrm{FeOOH}$ to $\mathrm{LNO}$, in good agreement with the DFT calculations as shown in Figure S28b. The Ni K-edge extended XAFS (EXAFS) $k^{2} \chi(R)$ spectra of LNO and FeLNO are shown in Figure 4(b), and there are two significant peaks at near $1.5 \AA$ and $3.1 \AA$, which can be assigned to $\mathrm{Ni}-\mathrm{O}$ peak and Ni-La peak, respectively [18]. The intensity of $\mathrm{Ni}$ La peak of Fe-LNO decreases slightly compared with that of LNO, and there is no obvious position shift; however, the $\mathrm{Ni}-\mathrm{O}$ peak of Fe-LNO is positively shifted compared with that of LNO, which further indicates that $\mathrm{FeOOH}$ can weaken the Ni-O bond of LNO.

2.5. The Evidences of LOER Promoted by FeOOH. OER electrocatalytic activity with $\mathrm{pH}$ dependence indicates the existence of NCPET step and confirms the presence of decoupled proton-electron transfer step. The previous studies have found that the LOER (especially in perovskite) shows significant $\mathrm{pH}$ dependence $[11,42]$. In $\mathrm{pH}$ dependence tests, it is important to have a proper Tafel range to prevent the effect of electrolyte mass transfer efficiency [68]. We firstly plot the rainbow map including current density, voltage, and $\mathrm{pH}$ as shown in Figure 5(a). It is found that the $\mathrm{pH}$ dependence increased significantly after $1.60 \mathrm{~V}$ vs. RHE. Thus, the final Tafel range of LNO is locked in $1.53 \mathrm{~V} \sim 1.60 \mathrm{~V}$ vs. RHE, which is consistent with previous reports $[11,36]$. The oxide peak of Fe-LNO shows positive shift at $1.51 \mathrm{~V} \sim 1.55 \mathrm{~V}$ (vs. RHE). In order to improve accuracy, we finally choose two potentials of 1.55 and $1.60 \mathrm{~V}$ (vs. RHE) to compare $\mathrm{pH}$ dependence of Fe-LNO and LNO as shown in Figure 5(b). Obviously, the $\mathrm{pH}$ dependence of Fe-LNO increases a factor of 1.5 compared with LNO, and this well confirms that the promotion of hydroxyl adsorption 


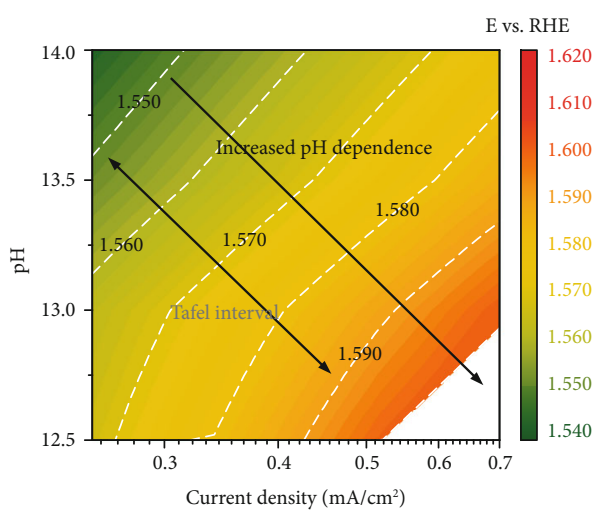

(a)

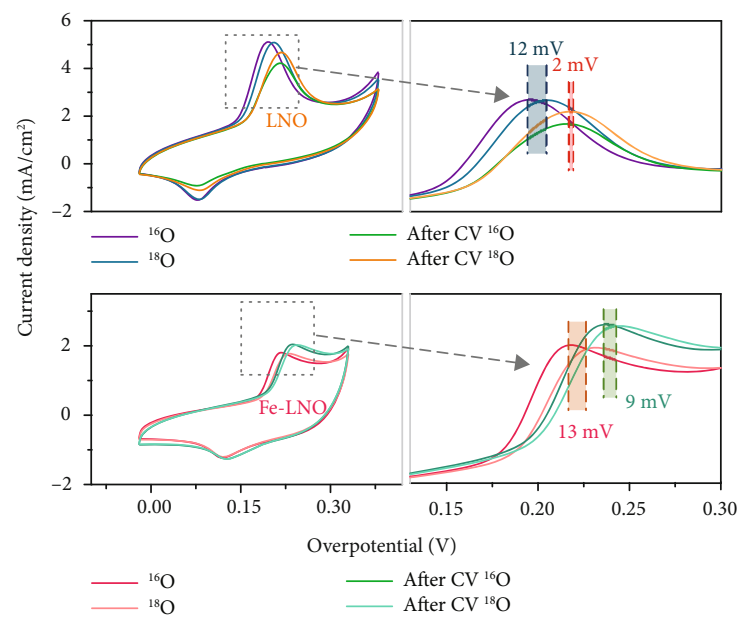

(d)

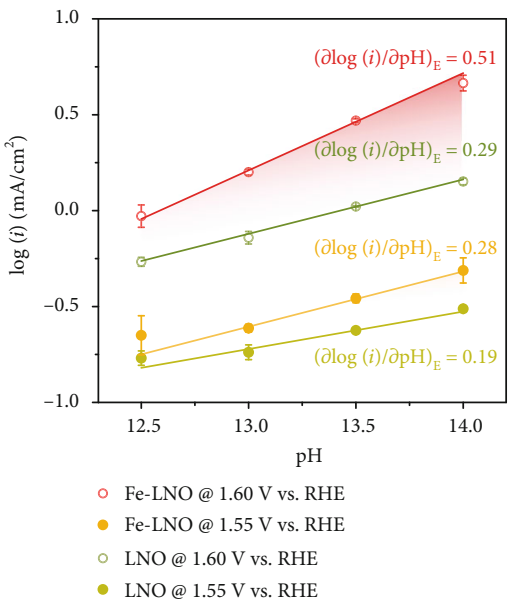

(b)
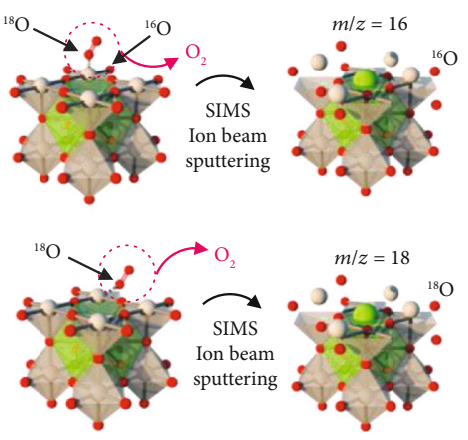

(e)

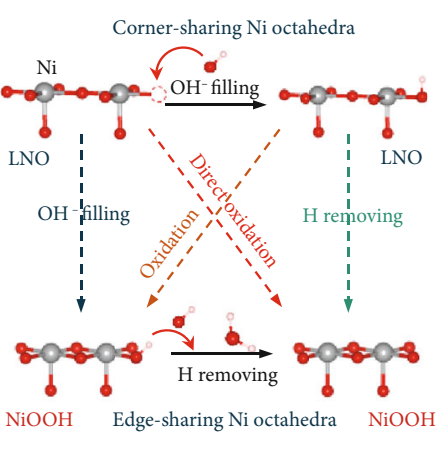

(c)

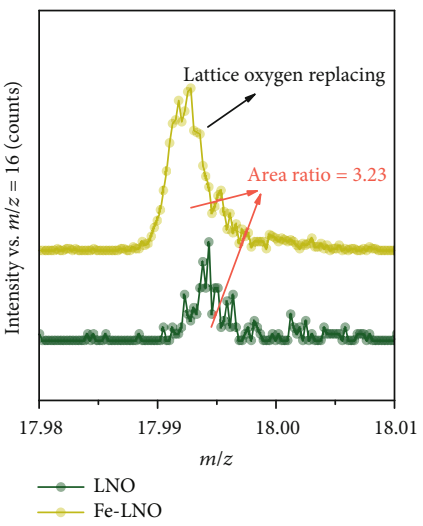

(f)

Figure 5: Evidences of LOER in Fe-LNO and LNO. (a) The rainbow map contains current density, voltage, and pH of LNO. (b) Specific OER catalytic activity at $1.55 \mathrm{~V}$ and $1.60 \mathrm{~V}$ versus RHE as a function of $\mathrm{pH}$. (c) Two oxidation mechanisms of LNO and NiOOH. (d) Cyclic voltammograms in $0.1 \mathrm{~mol} / \mathrm{L} \mathrm{Li}^{18} \mathrm{OH}$ and $\mathrm{LiOH}$ of catalysts. (e) Illustration of the mechanism of ${ }^{18} \mathrm{O}$ labeled TOF-SIMS. (f) The ${ }^{18} \mathrm{O}$ signal in LNO and Fe-LNO (the intensity has been normalized by ${ }^{16} \mathrm{O}$ signal).

by $\mathrm{FeOOH}$ is an effective way to promote the LOER of perovskite. In addition, the specific OER catalytic activity (current normalized by geometry area) at $1.60 \mathrm{~V}$ (vs. RHE) as a function of $\mathrm{pH}$ is shown in Figure S34, and the same conclusion can be drawn.

To further confirm that $\mathrm{FeOOH}$ promotes LOER of LNO, the ${ }^{18} \mathrm{OH}^{-}$oxidation process in OER was detected by ${ }^{18} \mathrm{O}$ labeling experiment. Figure $5(\mathrm{~d})$ shows the $1^{\text {st }}$ and $50^{\text {th }}$ cyclic voltammograms (CVs) of LNO and Fe-LNO in $0.1 \mathrm{M}$ $\mathrm{Li}^{18} \mathrm{OH}$ and $0.1 \mathrm{M} \mathrm{Li}^{16} \mathrm{OH}$ solutions. The $1^{\text {st }} \mathrm{CVs}$ of LNO and $\mathrm{Fe}$-LNO both show an obvious positive shift of oxidation peak in $0.1 \mathrm{M} \mathrm{Li}^{18} \mathrm{OH}$ solution compared with that in $0.1 \mathrm{M}$ $\mathrm{Li}^{16} \mathrm{OH}$ solution. This phenomenon almost disappears for the $50^{\text {th }} \mathrm{CVs}$ of LNO in $0.1 \mathrm{M} \mathrm{Li}^{18} \mathrm{OH}$ and $0.1 \mathrm{M} \mathrm{Li}^{16} \mathrm{OH}$ solutions, but it still exists for the Fe-LNO sample. To elucidate the different situations of LNO and Fe-LNO, we summarized two mechanisms of $\mathrm{LNO}$ and $\mathrm{NiOOH}$ as shown in Figure 5(c) [69]. As we all know, during the oxidation, the
LNO undergoes $\mathrm{OH}^{-}$oxidation step in $\mathrm{O}$ vacancy and $\mathrm{H}$ removing step [70], so the positive shift of oxidation peak in $0.1 \mathrm{M} \mathrm{Li}{ }^{18} \mathrm{OH}$ solution compared with that in $0.1 \mathrm{M}$ $\mathrm{Li}^{16} \mathrm{OH}$ solution indicates that the $\mathrm{OH}^{-}$filling step is greatly influenced by isotope effect. After 50 cycles, the LNO becomes insensitive to ${ }^{18} \mathrm{OH}^{-}$because of the structure change; however, Fe-LNO still is sensitive to ${ }^{18} \mathrm{OH}^{-}$after 50 cycles, further indicating that $\mathrm{FeOOH}$ can enhance the LOER of LNO by the promotion of hydroxyl adsorption and prevention of the structure change of LNO from corner sharing to edge sharing, which is consistent with the results of in situ Raman spectroscopy. Moreover, we designed ${ }^{18} \mathrm{O}$ isotope labeling mass spectrometry to confirm the existence of ${ }^{18} \mathrm{O}$ in LNO and Fe-LNO during OER as shown in Figures 5(e) and 5(f). The significant peak of ${ }^{18} \mathrm{O}$ in both LNO and FeLNO shows that the lattice oxygen exchange occurred during OER, which is consistent with the $\mathrm{pH}$ dependence test and ${ }^{18} \mathrm{O}$ labeling test. As shown in Figure 5(f), the peak area of 


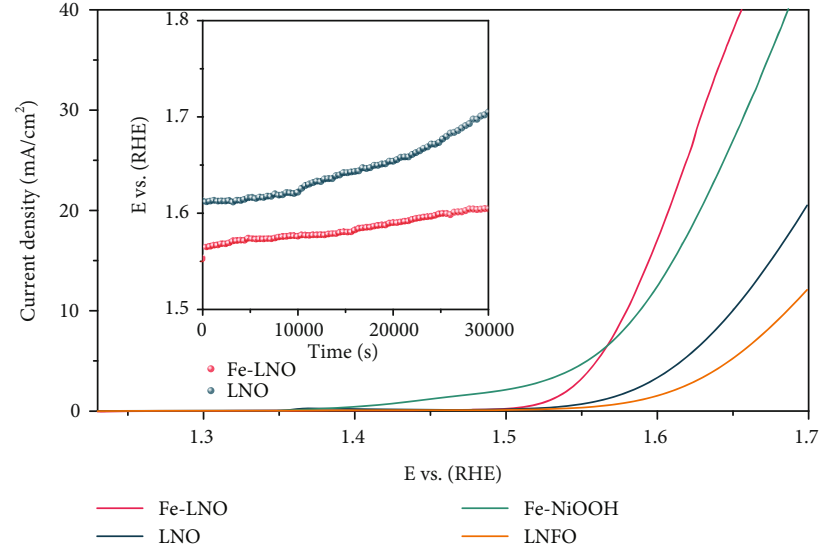

(a)

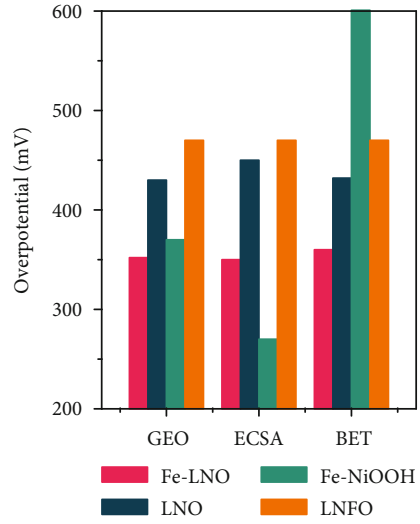

(b)

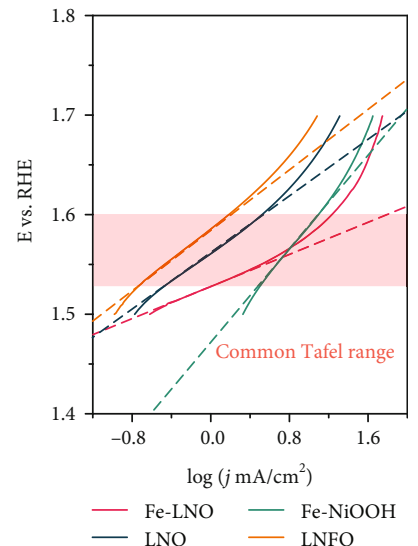

(c)

\begin{tabular}{lccc}
\hline Sample name & Fe-LNO & LNO & Fe-NiOOH \\
Tafel slope & $42 \mathrm{mV} / \mathrm{dec}$ & $71 \mathrm{mV} / \mathrm{dec}$ & $120 \mathrm{mV} / \mathrm{dec}$ \\
Potential normalized with geometry @ $10 \mathrm{~mA} / \mathrm{cm}^{2}$ & $1.58 \mathrm{~V} \mathrm{vs.} \mathrm{RHE}$ & $1.65 \mathrm{~V} \mathrm{vs.} \mathrm{RHE}$ & $72 \mathrm{mV} / \mathrm{dec}$ \\
TOF @ $1.60 \mathrm{~V}$ vs. RHE & $39.62 \mathrm{O}_{2} \mathrm{~S}^{-1}$ & $7.72 \mathrm{O}_{2} \mathrm{~S}^{-1}$ & $1.59 \mathrm{~V} \mathrm{vs.} \mathrm{RHE}$ \\
\hline
\end{tabular}

(d)

FIGURE 6: Electrochemical performance characterizations. (a) Oxygen evolution results and catalytic activities for LNO, Fe-LNO, Fe-NiOOH, and LNFO, activities measured in $1 \mathrm{M} \mathrm{KOH}$ at $10 \mathrm{mV} \mathrm{s}^{-1}$ and the chronopotentiometry of LNO and Fe-LNO measured at $10 \mathrm{~mA} \mathrm{~cm}^{-2}$. (b) The GEO, ECSA, and BET normalized overpotentials of various catalysts. (c) Tafel plots of the specific activity of each catalyst. (d) The Tafel slope, overpotential with geometry, and TOF of catalysts.

Fe-LNO is 3 times higher than that of LNO, which also confirmed $\mathrm{FeOOH}$ nanoclusters for optimizing the LOER of LNO.

2.6. Superior Electrochemical Performance of Fe-LNO. The catalytic activity and stability of Fe-LNO catalysts were assessed in the solution of $1.0 \mathrm{M} \mathrm{KOH}$ by cyclic voltammetry and chronopotentiometric at $10 \mathrm{~mA} / \mathrm{cm}^{2}$ (current is normalized to geometric surface area of electrode) with a procedure similar to benchmarking studies for electrocatalysts [71]. In order to highlight the advantages of Fe-LNO, here, the catalytic performance of Fe-LNO catalysts was compared with those of $\mathrm{LNO}, \mathrm{Fe}-\mathrm{NiOOH}$, and $\mathrm{La}_{2} \mathrm{NiFeO}_{6}$ (LNFO). Figure 6(a) shows the chronopotentiometric and OER polarization curves of the series of catalysts. The $\mathrm{Fe}-\mathrm{NiOOH}$ catalyst shows high OER catalytic activity with an overpotential of $360 \mathrm{mV}$ at $10 \mathrm{~mA} \mathrm{~cm}^{-2}$ without IR correction. The LNO catalyst exhibits an overpotential of $420 \mathrm{mV}$ at $10 \mathrm{~mA} \mathrm{~cm}^{-2}$, which is consistent with the earlier reports [72, 73]. However, the LNFO sample shows a poor performance compared with Fe-LNO, and it needs $460 \mathrm{mV}$ to reach $10 \mathrm{~mA} \mathrm{~cm}^{-2}$. The above results show that the LNFO still cannot enhance the catalyst performance by doping Fe into LNO crystalline, which is also reported in a previous work [74]. Among the above various catalysts, the Fe-LNO showed the highest OER catalytic activity with the lowest overpotential of $350 \mathrm{mV}$ to reach $10 \mathrm{~mA} \mathrm{~cm}^{-2}$, especially in high voltage range, as shown in Figure 6(a). The above results confirm that $\mathrm{FeOOH}$ can activate LOER of LNO by promoting hydroxyl adsorption, showing 5 times increase at $1.60 \mathrm{~V}$ (vs. RHE) compared with LNO. Furthermore, the effect of deposition time of $\mathrm{FeOOH}$ on LNO for 1 20 min on OER cata- lytic performance was investigated as shown in Figure S35a, which shows that the Fe-LNO owns the highest catalytic activity when the deposition time is $5 \mathrm{~min}$. The stability tests of LNO and Fe-LNO are shown in the inset in Figure 6(a), which shows that the Fe-LNO owns much higher stability than LNO. So, the decoration of $\mathrm{FeOOH}$ can significantly improve the stability of LNO. In addition, we studied other similar perovskites modified by metal hydroxy oxides, such as CoOOH-LNO, MnOOH-LNO, and FeOOH-(Sr) $\mathrm{LaCoO}_{3}$, and their catalytic performance for OER also can be obviously improved as shown in Figure S41-S44. Therefore, the above results show that the decoration of metal hydroxy oxide is a universal method to improve the electrocatalytic performance of perovskite for OER $[73,75]$.

To evaluate the intrinsic performance, the electrochemically active surface area (ECSA) and Brunauer-EmmettTeller surface area (BET) normalized LSVs of various catalysts were measured as shown in Figure S45, which shows that the Fe-LNO owns the highest BET normalized OER activity and $\mathrm{Fe}-\mathrm{NiOOH}$ owns the highest ECSA normalized OER activity. The geometry area (GEO), ECSA, and BET normalized overpotentials of various catalysts are shown in Figure 6(b), and the LNFO is utilized as a reference catalyst with an overpotential of $460 \mathrm{mV}$. The Fe-LNO owns the lowest GEO and BET normalized overpotentials, and Fe$\mathrm{NiOOH}$ owns the lowest ECSA normalized overpotentials. The above results show that the decoration of $\mathrm{FeOOH}$ did not enhance the ECSA of LNO but slightly decreased (the double-layer capacitance decreases from 2.98 to $1.83 \mathrm{mF} \mathrm{cm}^{-2}$ ), so the $\mathrm{FeOOH}$ cannot increase the active sites of LNO, and this is consistent with previous works 
$[43,76]$. The Fe-NiOOH exhibits the lowest ECSA area (Figure S48b), which is attributed to the different mechanisms of double-layer capacitance between metal oxyhydroxide and oxide [77]. The BET normalized OER activity of Fe-LNO is almost the same as GEO and ECSA normalized OER activities. But $\mathrm{Fe}-\mathrm{NiOOH}$ showed the poorest BET normalized OER activity, and this can be attributed to the maximum specific surface area of $\mathrm{Fe}$ $\mathrm{NiOOH}$, which was nearly 20 times than that of LNO $\left(9.34 \mathrm{~m}^{2} / \mathrm{g}\right)$. So, the above results show that the catalytic performance of the Fe-LNO catalyst is much better than other catalysts, which shows that the intrinsic activity of perovskite can be effectively improved by the strategy of promoting hydroxyl adsorption.

The Tafel slope represents the OER kinetics of the catalyst. The Fe-LNO exhibits the smallest Tafel slope of $42 \mathrm{mV} / \mathrm{dec}$ as shown in Figure 6(c), which is much smaller than those of LNO and LNFO (71 mV/dec and $72 \mathrm{mV} / \mathrm{dec})$, especially that of Fe-NiOOH $(120 \mathrm{mV} / \mathrm{dec})$. So, the Fe-LNO shows the excellent OER kinetic. Finally, we compared the turnover frequencies (TOFs) of LNO, Fe-LNO, Fe-NiOOH, and LNFO catalysts as listed in Figure 6(d), and Fe-LNO owns the biggest TOF value, further confirming that high OER catalytic activity of Fe-LNO is attributed to the promotion of hydroxyl adsorption that is an effective strategy to optimize OER of perovskite.

\section{Conclusions}

In summary, we have proposed an effective and feasible strategy to directly optimize the LOER of perovskite by the decoration of iron oxyhydroxide on the surface of perovskite. The designed Fe-LNO catalyst exhibited superior catalytic performance with five times OER catalytic activity enhancement and excellent long-term durability compared with the original LNO perovskite. Combining the structural characterization and DFT theoretical calculations, we well demonstrated that the FeOOH could strongly affect the coordination modes of anions and accelerate the hydroxyl adsorption step of LOER for LNO. Furthermore, the experimental results and DFT calculations both proved that the decoration of $\mathrm{FeOOH}$ could realize the positive shift of the $\mathrm{O} 2 \mathrm{p}$ band of LNO and accordingly could obviously decrease the energy barrier of LOM. The strategy of iron oxyhydroxide modification will open a surface engineering route to promote and optimize the LOER of perovskite and other metal oxides.

\section{Materials and Methods}

4.1. General. All chemicals were used as they were received from manufacturers. Lanthanum(III) nitrate hexahydrate (AR) and ferrous sulfate heptahydrate (AR) were purchased from Macklin. Nickel(II) nitrate hexahydrate (AR), iron(III) nitrate nonahydrate (AR), and potassium hydroxide (metal basis $99.999 \%$ ) were purchased from Sigma-Aldrich. Citric acid monohydrate (AR) and absolute 200 proof ethanol were purchased from LookChem. $5 \mathrm{wt} \%$ Nafion solution in lower alcohols was obtained from Sigma-Aldrich. Millipore highpurity water (DI water, $18 \mathrm{M} \Omega$ ) was used in this study.

4.2. Catalyst Synthesis. $\mathrm{LaNiO}_{3}$ (LNO) powder was synthesized by a Pechini method [14], followed by crystallization and annealing. Typically, A and B site nitrate salts with stoichiometric ratios were dissolved in water to form a solution, and the total concentration of metal salts was $0.2 \mathrm{M}$. Then, citric acid was added with a concentration of $0.2 \mathrm{M}$. The solution was stirred at $500 \mathrm{rpm}$ for $1 \mathrm{~h}$ to ensure complete chelation of the metal cations. The clarified solution was dried at $120^{\circ} \mathrm{C}$ for $2 \mathrm{~h}$ to obtain colloid-like substances and then transfered to a tubular furnace. The heating rate was $1^{\circ} \mathrm{C} \mathrm{min}{ }^{-1}$, and the gel was combusted on a hot plate at $400^{\circ} \mathrm{C}$ to form mixed metal oxide precursor particles. This step was to avoid possible explosions from rapid evolution of gasses upon combustion. Finally, the precursor particles were crystallized at $800^{\circ} \mathrm{C}$ for $4 \mathrm{~h}$, slowly cooling to room temperature.

$\mathrm{La}_{2} \mathrm{NiFeO}_{6}$ (LNFO) powder was synthesized by the same method as that of LNO. XRD of LNFO is shown in Figure S9b, and the negative shift of the peak of LNFO confirmed the success of Fe doping, which is consistent with previous reports $[78,79]$.

FeOOH-LaNiO $\mathrm{L}_{3}$ (Fe-LNO) was obtained by a simple deposition way. Typically, $0.246 \mathrm{~g}$ of LNO sample was immersed into a $100 \mathrm{ml} \mathrm{FeSO} \cdot 6 \mathrm{H}_{2} \mathrm{O}(2.78 \mathrm{~g})$ aqueous solution, then was stirred under RT for $5 \mathrm{~min}$. The $\mathrm{pH}$ of solution must be held around 4 to prevent LNO from being etched. Then, the above solution was centrifuged for three times, and the obtained solid powders were further oxidized at $70^{\circ} \mathrm{C}$ in air to synthesize Fe-LNO.

$\mathrm{NiOOH}$ was obtained by a chemical coprecipitation way. The $\mathrm{Ni}\left(\mathrm{NO}_{3}\right)_{2}$ and $\mathrm{KOH}$ in stoichiometric ratios were dissolved in water to form a solution. Then, the above solution was centrifuged for three times to synthesize $\mathrm{NiOOH}$ powder. The decoration of $\mathrm{FeOOH}$ on $\mathrm{NiOOH}(\mathrm{Fe}-\mathrm{NiOOH})$ was synthesized by the reaction of $\mathrm{Ni}\left(\mathrm{NO}_{3}\right)_{2}$ and $\mathrm{KOH}$, and the obtained $\mathrm{Ni}(\mathrm{OH})_{2}$ was the typical $\beta$ phase, with high specific area of $170 \mathrm{~m}^{2} / \mathrm{g}$, as shown in Figure S5. The obtained $\beta$ $\mathrm{Ni}(\mathrm{OH})_{2}$ was then further oxidized to $\mathrm{NiOOH}$ by cycle voltammetry. Finally, the deposition of $\mathrm{FeOOH}$ has the same procedure as that of Fe-LNO.

4.3. Material Characterization. The surface morphology of catalysts was characterized by a Zeiss Sigma field emission scanning electron microscopy (FE-SEM, JSM-6330F). The structure of samples was measured with transmission electron microscopy (TEM), JEM-2010HR, and high-resolution TEM (HRTEM, $200 \mathrm{kV}$ or $300 \mathrm{kV}$ ), and the fast fourier transform (FFT) images were obtained by Digital Micrograph software. The specific surface area was characterized by nitrogen adsorption-desorption measurements (Micromertics ASAP 2020M) using the Brunauer-Emmett-Teller (BET) method. $2.0 \mathrm{~g}$ of the sample was pretreated at $110^{\circ} \mathrm{C}$ for at least $2 \mathrm{~h}$ before $\mathrm{N}_{2}$ physisorption measurements at $77 \mathrm{~K}$. X-ray photoelectron spectroscopy (XPS) was performed by an ESCA Lab250 X-ray photoelectron spectrometer. All XPS spectra were corrected using the C 1 s line at 
$284.8 \mathrm{eV}$, and the curve fitting and background subtraction were accomplished. X-ray absorption near edge structure (XANES) measurements of $\mathrm{Ni}$ and $\mathrm{Fe} \mathrm{K}$-edge were conducted on the 06ID superconducting wiggler sourced hard $\mathrm{X}$-ray microanalysis beamline Beijing Synchrotron Radiation Facility. Each sample spectrum was collected in a transmission mode for 2 comparison and monochromatic energy calibration. The catalyst structure was examined by performing $\mathrm{X}$-ray diffraction with the Bruker-D8 advance diffractometer, and the measurements were performed at $298 \mathrm{~K}$ in ambient conditions while the instrument operated at $40 \mathrm{kV}$ and $15 \mathrm{~mA}$ using $\mathrm{Cu} \mathrm{K} \alpha$ radiation (1.54 Å wavelength). Catalyst powder was exposed to ambient air and scanned over $20 \sim 80^{\circ}$ in $0.02^{\circ}$ increments with a step time of $0.2 \mathrm{~s}$. The LNO was scanned over $10 \sim 105^{\circ}$ in 0.02 increments with a step time of $95 \mathrm{~s}$ to get high-quality PXRD pattern for further Rietveld refinement. The Rietveld refinement was performed with the FullProf refinement program [80]. The crystal structure of the $\mathrm{R} \overline{3} \mathrm{c}$ space group was used as a starting model of LNO [81].

4.4. Electrochemical Characterization. The catalyst inks were obtained by mixing $3 \mathrm{mg}$ catalyst powders with $1 \mathrm{ml} \mathrm{NaOH}$ solution $(1.0 \mathrm{M})$ and then were neutralized with $0.05 \mathrm{wt} \%$ Nafion solution. The catalyst inks must be bath sonicated for at least half an hour before use. Ten microliters of catalyst inks was drop cast onto $5 \mathrm{~mm}$ glassy carbon electrode (GCE) and dried with infrared lamp. Before use, the GCE was polished using $0.05 \mu \mathrm{m}$ alumina powder and washed with fresh high-purity water and ethanol mixed solution; then, it was sonicated in a fresh solution of water, and finally, it was dried with infrared lamp. The above steps were used to clean all GCEs before drop casting. The $\mathrm{pH}$ dependence test and other electrochemical characterizations were detailed in supporting information (Figure S38).

Electrochemical performance of catalyst was assessed on a CHI-760E workstation at room temperature. The electrolyzer cell of three electrodes was used for all experiments. The reference electrode was a $\mathrm{KCl}$ saturated calomel $\mathrm{Hg} / \mathrm{Hg}_{2} \mathrm{Cl}_{2}$ electrode, the Pt plate electrode served as the counter electrode, and GCE coated with catalysts was used as the working electrode. All potentials were measured vs. $\mathrm{Hg} / \mathrm{Hg}_{2} \mathrm{Cl}_{2}$, but they were used versus reversible hydrogen electrode (RHE) and were determined by $U_{\mathrm{RHE}}=U_{\mathrm{SCE}}+0.241+0.059 * \lg ($ $\mathrm{pH})$.

Cycle voltammetry of the $\mathrm{OH}^{-}$adsorption test was performed from $0.23 \mathrm{~V}$ to $1.57 \mathrm{~V}$ vs. RHE at a scan rate of $10 \mathrm{mV} \mathrm{s}^{-1}$, and the OER polarization curve was measured from $1.23 \mathrm{~V}$ to $1.73 \mathrm{~V}$ vs. RHE at the same rate including the $\mathrm{pH}$ dependence test. All the curves were using the $10^{\text {th }}$ cycle of the cycle voltammetry data and also compared the performance of the $1^{\text {st }}$ cycle. The current density at $10 \mathrm{~mA} \mathrm{~cm}^{-1}$ was used for the comparison of OER catalytic activities; data presented in this report are the average of at least three tests on fresh electrodes. The ${ }^{18} \mathrm{O}$ labeled $\mathrm{LiOH}$ was synthesized by hydrogen substitution of heavy oxygen water $\left(\mathrm{H}_{2}{ }^{18} \mathrm{O}\right.$, Macklin); the process proceeds slowly in an ice bath and accesses the $\mathrm{N}_{2}$ during reaction to prevent the formation of $\mathrm{Li}_{2} \mathrm{O}$. The obtained $\mathrm{Li}^{18} \mathrm{OH}$ was dissolved in high-purity water $\left(\mathrm{H}_{2}{ }^{16} \mathrm{O}\right)$ to reach $\mathrm{pH}$ of 13 . The ${ }^{16} \mathrm{O}$ labeled $\mathrm{LiOH}$ was synthesized by the same way to compare the barrier of oxidation. Cycle voltammetry was performed from $1.23 \mathrm{~V}$ to $1.61 \mathrm{~V}$ vs. RHE for LNO and $1.23 \mathrm{~V}$ to $1.56 \mathrm{~V}$ vs. RHE for Fe-LNO at a scan rate of $10 \mathrm{mV} \mathrm{s}^{-1}$ to prevent intense oxidation. The further cycle voltammetry for oxidation was performed from $1.27 \mathrm{~V}$ to $1.87 \mathrm{~V}$ vs. RHE for 50 cycles to detect the structure change of LNO.

4.5. In Situ Raman Spectroscopy. All the in situ Raman spectroscopy experiments were carried out at an inVia confocal Raman microscope, Renishaw. The water immersion objective is $50 \mathrm{x}$ and wrapped in a Teflon film $(0.025 \mathrm{~mm}$ in thickness) to avoid direct contact between lens and electrolyte (Figure S22). The laser power was $532 \mathrm{~nm}$ with $0.5 \%$ power (prevent the Teflon film from being oxidized) at grating of $1800 \mathrm{~mm}^{-1}$. The silicon peak of $520 \mathrm{~cm}^{-1}$ is correct before testing to ensure the instrument accuracy. All the in situ electrochemical characterizations were using a three-port electrolyzer, with the same reference with previous characterizations. The electrolyte was using the metal basis $\mathrm{KOH}$ of $1.0 \mathrm{M}$; the open circuit represents to the powder immersed in $\mathrm{KOH}$ while the $1.23 \mathrm{~V}$ and $1.73 \mathrm{~V}$ vs. RHE were used to detect the $\mathrm{OH}^{-}$filling step and material changes during OER, respectively.

4.6. $\mathrm{OH}^{-}$Adsorption $\mathrm{pH}$ Test. The $\mathrm{OH}^{-}$adsorption $\mathrm{pH}$ test was performed with a $\mathrm{pH}$ meter (PHS-2F). $1 \mathrm{M}$ metal basis $\mathrm{KOH}$ was used for detecting. The solution of $10 \mathrm{ml} \mathrm{KOH}$ contains $100 \mathrm{mg}$ total weight of catalysts, and the obtained catalyst ink was sonicated $5 \mathrm{~min}$ until dispersible, then precipitate to test the $\mathrm{pH}$ of supernatant. The mole amount of $\mathrm{OH}^{-}$adsorption was calculated by converted $\mathrm{OH}^{-}$concentration. The initial $\mathrm{pH}$ value for all the samples is 13.28 , while the end $\mathrm{pH}$ values are 13.26, 13.17, and 12.96 for LNO, Fe$\mathrm{LNO}$, and $\mathrm{FeOOH}$, respectively. The formula is shown as follows:

$$
\frac{\left(10^{14-\mathrm{pH}_{\text {intial }}}-10^{14-\mathrm{pH}_{\text {final }}}\right) * V_{\text {electrolyte }}}{m_{\text {sample }} *\left(1 / M_{\text {sample }}\right)},
$$

where $V$ denotes the volume of the electrolyte and $m$ and $M$ denote the mass and relative molecular mass of the samples, respectively.

4.7. Time-Dependent ICP-AES and ICP-MS Characterizations. The characterizations of time-dependent inductively coupled plasma-atomic emission spectrometry (ICP-AES) and inductively coupled plasma-mass spectrometer (ICP-MS) were carried out with iCAP Qc and IRIS(HR), TJA, respectively. The chronopotentiometry was measured at $10 \mathrm{~mA} / \mathrm{cm}^{2}$ in $1 \mathrm{M} \mathrm{KOH}$ solution of $10 \mathrm{ml} .1 \mathrm{ml}$ of electrolyte solution for OER was taken to dilute to $10 \mathrm{ml}$ with $1 \mathrm{moll}^{-1} \mathrm{HNO}_{3}$ for the ICP test.

4.8. Secondary Ion Mass Spectroscopy (SIMS) Characterization. SIMS was conducted to determine the ${ }^{18} \mathrm{O}$ and ${ }^{16} \mathrm{O}$ isotopes in catalysts using a TOF-SIMS ion tof Gmhb 5 device. Firstly, the catalysts were dispersed on Ti foil 
$(5 \mathrm{~mm} * 5 \mathrm{~mm})$ and were activated using cyclic voltammetry (CV) from 0.80 to $1.60 \mathrm{~V}$ (vs. RHE) at a scan rate of $10 \mathrm{mV} \mathrm{s}^{-1}$ for 50 cycles in $1 \mathrm{M} \mathrm{Li}^{18} \mathrm{OH}$ aqueous solution. Then, rinsing with ${ }^{16} \mathrm{O}$ water, the catalysts were finally heated at $65^{\circ} \mathrm{C}$ for $6 \mathrm{~h}$ to remove adsorbed $\mathrm{H}_{2}{ }^{18} \mathrm{O}$.

4.9. Density Function Theory Calculations and Surface Models. Spin-polarized density functional theory (DFT) calculations were performed in the plane wave and ultrasoft pseudopotential as implemented in Quantum ESPRESSO [82]. The adsorption energies were calculated using the Grimme- $\mathrm{D}^{3}$ vdw-correction with Perdew-Burke-Ernzerhof (PBE) exchange functional correction [83]. The effective $U$ $J$ terms, from linear response theory [84], were 3.5 and 6.6 for $\mathrm{Fe}$ and $\mathrm{Ni}$, respectively. The kinetic energy cutoffs of $25 \mathrm{Ry}$ and $225 \mathrm{Ry}$ were chosen for the wave functions and augmented charge densities. All the atomic structures for the models were fully relaxed with self-consistency criteria of $10^{-5} \mathrm{Ry}$, and all atomic coordinates were converged to within $10^{-3} \mathrm{Ry} / \mathrm{bohr}$ for maximal components of forces. The occupancy of the one-electron states was calculated using an electronic temperature of $k_{B} T=0.01$ Ry for surfaces and $10^{-3} \mathrm{Ry}$ for molecules in vacuum. All energies were extrapolated to $T=0 \mathrm{~K}$. The vacuum slab of $12 \AA$ was used for surface isolation to prevent interaction between two surfaces. All the atoms were relaxed to simulate a bulk structure, and all atoms were fixed except the top two layers in the slab system. Reciprocal space was sampled by the $\Gamma$-centered Monkhorst-Pack scheme with (lattice parameters $\times k$ ) $~ 30$ to compare the energy differences. Due to the complex structure of the R $\overline{3} c$ space group, we use the cubic phase for all calculations. The cell parameter of LNO is $a=b=c=3.86 \AA$, which agrees well with experiment [54]. Fe-LNO was built by supercell matching; the lattice mismatching error was less than $8 \%$. The calculation of the OER pathway was detailed in supporting information (Figures S18-S29).

\section{Conflicts of Interest}

The authors declare no competing interests.

\section{Authors' Contributions}

G.R. Li and J.W. Zhao conceived the idea and designed the experiments. C.F. Li, Z.X. Shi, and J.L. Guan conducted the experiments. All authors contributed equally to the writing of the manuscript. Jia-Wei Zhao and Cheng-Fei Li contributed equally to this work.

\section{Acknowledgments}

Financial support for this work was provided by the National Basic Research Program of China (2016YFA0202603), NSFC (21821003 and 91645104), Science and Technology Program of Guangzhou (201704030019), Natural Science Foundation of Guangdong Province (2017A010103007), and Guangdong Science and Technology Innovation Leading Talent Fund (2016TX03N187).

\section{Supplementary Materials}

Figure S1: $\mathrm{pH}$ values of the different solutions: (1) $\mathrm{H}_{2} \mathrm{O},(2)$ $\mathrm{Fe}\left(\mathrm{NO}_{3}\right)_{3}$ solution, (3) $\mathrm{FeCl}_{3}$ solution, and (4) $\mathrm{FeSO}_{4}$ solution. All salt solutions have the same mass: $100 \mathrm{mg}$ Fe salt dissolved in $10 \mathrm{ml}$ deionized water. Figure S2: SEM images of LNO. The specific surface area is $9.34 \mathrm{~m}^{2} \mathrm{~g}^{-1}$. Figure S3: SEM images of Fe-LNO. The specific surface area is $14.77 \mathrm{~m}^{2} \mathrm{~g}^{-1}$. Figure S4: SEM images of $\mathrm{La}_{2} \mathrm{NiFeO}_{6}$. The specific surface area is $10.74 \mathrm{~m}^{2} \mathrm{~g}^{-1}$. Figure S5: SEM images of $\mathrm{NiOOH}$. The specific surface area is $170.58 \mathrm{~m}^{2} \mathrm{~g}^{-1}$. Figure S6: SEM images of $\mathrm{NiO}$. The specific surface area is $3.23 \mathrm{~m}^{2} \mathrm{~g}^{-1}$. Figure S7: HRTEM images of LNO, and the lattice constant was $0.38 \mathrm{~nm}$, close to the experimental value of $3.86 \AA$. Figure S8: Rietveld refined XRD patterns of LNO. The rhombohedral structure (space group: R3c) of LNO with a lattice constant of $a=b=5.457 \AA, c=13.180 \AA$. Figure S9: XRD patterns of Fe-LNO (a), $\mathrm{La}_{2} \mathrm{NiFeO}_{6}$ (b), $\mathrm{NiO}$ (c), and $\mathrm{NiOOH}(d)$. Figure S10: Raman spectra of LNO (a) and FeLNO (b). The peak at around $560 \mathrm{~cm}^{-1}$ is closest in shift to $\alpha$-FeOOH. Figure S11: (a) in situ Raman spectroscopic device photograph. The in situ Raman spectra of (b) LNO and (c) Fe-LNO at $1.73 \mathrm{~V}$ vs. RHE. Figure S12: high-resolution XPS spectra of (a) Ni 2p, La 3d, and (b) O 1s of LNO and FeLNO. Figure S13: the XPS survey spectra of the assynthesized LNO and Fe-LNO. Figure S14: (a) highresolution $\mathrm{O}$ 1s XPS spectra of $\mathrm{FeOOH}$. The ratios of peak areas of $\mathrm{H}_{2} \mathrm{O}: \mathrm{OH}-: \mathrm{O}_{2}{ }^{2-}$ is about $3.5: 3.5: 1$, which is higher than LNO but lower than Fe-LNO, proving that hydroxyl adsorption does not only come from FeOOH; (b) highresolution Fe 2p XPS spectra of FeOOH and Fe-LNO. Figure S15: projected density of states of $\mathrm{Ni}(3 \mathrm{~d})$ orbitals in bulk $\mathrm{NiO}_{5}$ (a) and surface $\mathrm{NiO}_{5}$ (b). All calculation results were normalized with the Fermi level. Figure S16: projected density of states of $\mathrm{O}(2 \mathrm{p})$ orbitals in bulk $\mathrm{NiO}_{5}$ (a) and surface $\mathrm{NiO}_{5}$ (b). All calculation results were normalized with the Fermi level. Figure S17: integral curve of Ni 3d density of states in bulk $\mathrm{NiO}_{5}$ (a) and surface $\mathrm{NiO}_{5}$ (b). Figure S18: the proposed two OER mechanisms of LNO with the same starting point $(\mathrm{Ni}-* \mathrm{OH})$. The dashed box represents the most important step in the adsorbate evolution mechanism and lattice oxygen participation mechanism. Figure S19: the free energies of LNO with the same starting point (the dashed box represents the most important step in the adsorbate evolution mechanism and lattice oxygen participation mechanism). Figure S20: Four concerted proton-coupled electron transfer mechanisms for OER occurring at Ni site (Ni) (in red) and possible sequential proton-electron transfers along the path, constructed with the assumption that the charge of the reaction intermediates does not exceed one electron. Figure S21: oxygen evolution reaction pathway of LNO, slab model (a), M-OH (b), M-O (c), M-OOH (d), and M-OO (e). All the structures are calculated in the same parameter. Figure S22: lattice oxygen participated oxygen evolution reaction pathway of LNO, slab model with lattice oxygen vacancy (a), $\mathrm{M}(\mathrm{Ov})-\mathrm{OH}+\mathrm{VO}(\mathrm{b}), \mathrm{M}(\mathrm{Ov})-* \mathrm{OH}-* \mathrm{OH}$ (c), $\mathrm{M}(\mathrm{Ov})-* \mathrm{OH}(\mathrm{d})$, and $\mathrm{M}(\mathrm{Ov})-* \mathrm{OO}(\mathrm{e})$. All the structures are calculated in the same parameter. Figure S23: bulk models of LNO with top view (a) and side view (b). (The 
green, red, and gray balls represent $\mathrm{La}, \mathrm{O}$, and $\mathrm{Ni}$ atoms, respectively. The lattice constant of unit cell is $a=b=c=$ $3.857 \AA$.) Figure S24: bulk models of $\mathrm{FeOOH}$ with top view (a) and side view (b). (The brown and red balls represent $\mathrm{Fe}$ and $\mathrm{O}$ atoms, respectively.) Figure S25: slab models of LNO with side view (a) and perspective view (b). The vacuum layer was $12 \AA$. The top layer of $\mathrm{NiO}_{5}$ is relax while other inner layer is fixed. Figure S26: slab models of Fe-LNO with side view (a) and left view (b). The vacuum layer was $12 \AA$. The whole $\mathrm{FeOOH}$ layer and the top layer of $\mathrm{NiO} 5$ are relax while other inner layers are fixed. The calculation of $* \mathrm{OH}$ adsorption energy is simulated by bulk catalysis. Figure S27: DFT calculated electronic structures for Figure 1. (a) The charge distribution of Fe-LNO; (b) the charge density difference on Fe-LNO: $\rho=\rho[\mathrm{Fe}-\mathrm{LNO}]+\rho(\mathrm{FeOOH})-\rho\left[\mathrm{LaNiO}_{3}\right]$; yellow and cyan isosurface represents electron accumulation and electron depletion, respectively. Figure S28: (a) top view of the charge density difference on Fe-LNO. (b) Isosurface $2 \mathrm{D}$ view of the surface $\mathrm{NiO}_{5}$. Figure S29: the free energy of $* \mathrm{OH}$ adsorption in $\mathrm{LNO}$ with different $* \mathrm{OH}$ coverages, $25 \%$ (a) $100 \%$ (b). The related change of free energy of reaction (c, d). The coverage of $100 \%$ is using a single unit cell to construct, while the $25 \%$ is using super cell with $2 * 2$ in the $x y$ axis. Figure S30: the images of SIMS tests of LNO (top), Fe-LNO (middle), and FeOOH (bottom). Figure S31: the area ratio of Fe-LNO and LNO supported on FeOOH. Figure S32: normalized Fe K-edge XANES spectra and EXAFS $k 2 \chi$ (k) Fourier transform (FT) spectra of FeOOH and Fe-LNO with Fe foil as a reference. Figure S33: the soft-XAFS spectrum of Fe-LNO. Figure S34: specific OER catalytic activity (current normalized by geometry area) at the current density at $1.60 \mathrm{~V}$ (versus $\mathrm{RHE}$ ) as a function of $\mathrm{pH}$. Figure S35: the effect of different deposition times of Fe on catalytic performance and the ratio of $\mathrm{Fe}$ to $\mathrm{Ni}$ at different deposition times. The ratio is obtained by ICP-AES, and it can be found that the ratio of $\mathrm{Fe}$ to $\mathrm{Ni}$ is the best at 0.12 . Figure S36: the OER activities of $\mathrm{FeOOH}-\mathrm{NiO}$ and $\mathrm{Fe}-\mathrm{LNO}$ normalized to the geometry area. $\mathrm{NiO}$ powder was synthesized using a Pechini method, followed by crystallization and annealing, as the same procedure of LNO. Figure S37: cyclic voltammetry stability tests of Fe-LNO (a) and LNO (b). A total of 50 cycles $\left(1.27 \mathrm{~V} \sim 1.62 \mathrm{~V}\right.$ vs. RHE) at a scan rate of $10 \mathrm{mV} \mathrm{s}^{-1}$ in $1.0 \mathrm{M}$ $\mathrm{KOH}$. Figure S38: CV measurements of $\mathrm{KOH}$ solution with different $\mathrm{pH}$ values recorded on (a) Fe-LNO and (b) LNO at $10 \mathrm{mV} \mathrm{s}^{-1}$. All the $\mathrm{KOH}$ was used in metal basis $99.999 \%$. The catalyst inks were mixed by $3 \mathrm{mg}$ catalyst powder with $1 \mathrm{ml} \mathrm{NaOH}$ neutralized $0.05 \mathrm{wt} \%$ Nafion solution and bath sonicated for at least half an hour. Three microliters of catalyst ink was drop cast onto $3 \mathrm{~mm}$ glassy carbon electrodes (GCE). Figure S39: CV measurements from $0.03 \mathrm{M} \mathrm{KOH}$ $(\mathrm{pH} 12.5)$ to $1 \mathrm{M} \mathrm{KOH}(\mathrm{pH}=14)$ recorded at $10 \mathrm{mV} \mathrm{s}^{-1}$ : (a) Fe-LNO; (b) LNO (all the $\mathrm{KOH}$ was used in metal basis 99.999\%). Figure S40: the OER catalytic activities of catalysts in $1.0 \mathrm{M} \mathrm{KOH}$ solution saturated with $\mathrm{O}_{2}$ and $\mathrm{N}_{2}$ : (a) LNO, (b) Fe-LNO. Figure S41: (a) the OER catalaytic activities of various samples $\left(\mathrm{LaNiO}_{3}, \mathrm{CrO}_{x} \mathrm{H}_{y}-\mathrm{LaNiO}_{3}, \mathrm{MnO}_{x} \mathrm{H}_{y}-\mathrm{LaNi}\right.$ $\mathrm{O}_{3}, \mathrm{FeO}_{x} \mathrm{H}_{y}-\mathrm{LaNiO}_{3}, \mathrm{CoO}_{x} \mathrm{H}_{y}-\mathrm{LaNiO}_{3}, \mathrm{NiO}_{x} \mathrm{H}_{y}-\mathrm{LaNiO}_{3}$, and $\mathrm{CuO}_{x} \mathrm{H}_{y}-\mathrm{LaNiO}_{3}$ ) normalized to the geometry area at a scan rate of $5 \mathrm{mV} \mathrm{s}^{-1}$ in $1.0 \mathrm{M} \mathrm{KOH}$. (b) The related Tafel curves of various samples. Figure S42: (a) the OER catalytic activities of samples $\mathrm{LaCoO}_{3}$ and $\mathrm{FeOOH}-\mathrm{LaCoO}_{3}$ normalized to the geometry area at a scan rate of $5 \mathrm{mV} \mathrm{s}^{-1}$ in $1 \mathrm{M}$ $\mathrm{KOH}$; (b) the related Tafel curve of samples. Figure S43: (a) the OER catalytic activities of samples $\mathrm{La}_{0.75} \mathrm{Sr}_{0.25} \mathrm{CoO}_{3}$ and FeOOH-La $\mathrm{La}_{0.75} \mathrm{Sr}_{0.25} \mathrm{CoO}_{3}$ normalized to the geometry area at a scan rate of $5 \mathrm{mV} \mathrm{s}^{-1}$ in $1.0 \mathrm{M} \mathrm{KOH}$; (b) the related Tafel curve of samples. Figure S44: (a) the OER catalytic activities of samples $\mathrm{La}_{0.5} \mathrm{Sr}_{0.5} \mathrm{CoO}_{3}$ and $\mathrm{FeOOH}-\mathrm{La}_{0.5} \mathrm{Sr}_{0.5} \mathrm{CoO}_{3}$ normalized to the geometry area at a scan rate of $5 \mathrm{mV} \mathrm{s}^{-1}$ in $1 \mathrm{M} \mathrm{KOH}$; (b) the related Tafel curve of samples. Figure S45: the OER activities of samples Fe-LNO, $\mathrm{La}_{2} \mathrm{NiFeO}_{6}$, $\mathrm{NiO}$, and $\mathrm{NiOOH}$ normalized to the BET surface area (a) and ECSA surface area (b). The conversion method is by dividing the geometric area directly by the corresponding ECSA and BET values. Figure S46: double-layer capacitance measurements for determining the electrochemically active surface area (ECSA) of LNO from cyclic voltammetry in 1.0 M KOH solution. (a) Typical cyclic voltammograms in the non-Faradaic region around $0.05 \mathrm{~V}$ relative to SCE at different scan rates $\left(0.01,0.02,0.03,0.04\right.$, and $\left.0.05 \mathrm{~V} \mathrm{~s}^{-1}\right)$; (b) the average of the cathodic and anodic charging current absolute values measured at $0.025 \mathrm{~V}$ (vs. SCE) plotted as a function of the scan rate. Figure S47: double-layer capacitance measurements for determining electrochemically active surface area (ECSA) of Fe-LNO from cyclic voltammetry in $1.0 \mathrm{M} \mathrm{KOH}$ solution. (a) Typical cyclic voltammograms in the nonFaradaic region around $0.05 \mathrm{~V}$ relative to SCE at different scan rates $\left(0.01,0.02,0.03,0.04\right.$, and $\left.0.05 \mathrm{~V} \mathrm{~s}^{-1}\right)$; (b) the average of the cathodic and anodic charging current absolute values measured at $0.025 \mathrm{~V}$ (vs. SCE) plotted as a function of the scan rate. Figure S48: double-layer capacitance measurements for determining electrochemically active surface area (ECSA) of Fe-NiOOH from cyclic voltammetry in 1.0 M KOH solution. (a) Typical cyclic voltammograms in the non-Faradaic region around $0.05 \mathrm{~V}$ relative to SCE at different scan rates $\left(0.01,0.02,0.03,0.04\right.$, and $\left.0.05 \mathrm{~V} \mathrm{~s}^{-1}\right)$; (b) the average of the cathodic and anodic charging current absolute values measured at $0.025 \mathrm{~V}$ (vs. SCE) plotted as a function of the scan rate. Figure S49: double-layer capacitance measurements for determining electrochemically active surface area (ECSA) of $\mathrm{La}_{2} \mathrm{NiFeO}_{6}$ from voltammetry in $1.0 \mathrm{M} \mathrm{KOH}$ solution. (a) Typical cyclic voltammograms in the non-Faradaic region around $0.05 \mathrm{~V}$ relative to SCE at different scan rates $\left(0.01,0.02,0.03,0.04\right.$, and $\left.0.05 \mathrm{~V} \mathrm{~s}^{-1}\right)$; (b) the average of the cathodic and anodic charging current absolute values measured at $0.025 \mathrm{~V}$ (vs. SCE) plotted as a function of the scan rate. Figure S50: XRD patterns of Fe-LNO after different cycle times. (Supplementary Materials)

\section{References}

[1] V. R. Stamenkovic, D. Strmcnik, P. P. Lopes, and N. M. Markovic, "Energy and fuels from electrochemical interfaces," Nature Materials, vol. 16, no. 1, pp. 57-69, 2017.

[2] J. Hwang, R. R. Rao, L. Giordano, Y. Katayama, Y. Yu, and Y. Shao-Horn, "Perovskites in catalysis and electrocatalysis," Science, vol. 358, no. 6364, pp. 751-756, 2017. 
[3] Z.-. P. Wu, X. F. Lu, S.-. Q. Zang, and X. W. (. D.). Lou, "NonNoble-Metal-Based electrocatalysts toward the oxygen evolution reaction," Advanced Functional Materials, vol. 30, no. 15, article 1910274, 2020.

[4] S. Geiger, O. Kasian, M. Ledendecker et al., "The stability number as a metric for electrocatalyst stability benchmarking," Nature Catalysis, vol. 1, no. 7, pp. 508-515, 2018.

[5] F. Song, L. Bai, A. Moysiadou et al., "Transition metal oxides as electrocatalysts for the oxygen evolution reaction in alkaline solutions: an application-inspired renaissance," Journal of the American Chemical Society, vol. 140, no. 25, pp. 7748-7759, 2018.

[6] W.-J. Yin, B. Weng, J. Ge, Q. Sun, Z. Li, and Y. Yan, "Oxide perovskites, double perovskites and derivatives for electrocatalysis, photocatalysis, and photovoltaics," Energy \& Environmental Science, vol. 12, no. 2, pp. 442-462, 2019.

[7] Y. Zhu, W. Zhou, and Z. Shao, "Perovskite/carbon composites: applications in oxygen electrocatalysis," Small, vol. 13, no. 12, article 1603793, 2017.

[8] W. Wang, M. Xu, X. Xu, W. Zhou, and Z. Shao, "Perovskite Oxide Based electrodes for high-performance photoelectrochemical water Splitting," Angewandte Chemie International Edition, vol. 59, no. 1, pp. 136-152, 2020.

[9] J. Suntivich, K. J. May, H. A. Gasteiger, J. B. Goodenough, and Y. Shao-Horn, "A perovskite oxide optimized for oxygen evolution catalysis from molecular orbital principles," Science, vol. 334, no. 6061, pp. 1383-1385, 2011.

[10] A. Grimaud, K. J. May, C. E. Carlton et al., "Double perovskites as a family of highly active catalysts for oxygen evolution in alkaline solution," Nature Communications, vol. 4, no. 1, p. 2439, 2013.

[11] A. Grimaud, O. Diaz-Morales, B. Han et al., "Activating lattice oxygen redox reactions in metal oxides to catalyse oxygen evolution," Nature Chemistry, vol. 9, no. 5, pp. 457-465, 2017.

[12] J. S. Yoo, X. Rong, Y. Liu, and A. M. Kolpak, "Role of lattice oxygen participation in understanding trends in the oxygen evolution reaction on perovskites," ACS Catalysis, vol. 8, no. 5, pp. 4628-4636, 2018.

[13] J. S. Yoo, Y. Liu, X. Rong, and A. M. Kolpak, "Electronic origin and kinetic feasibility of the lattice oxygen participation during the oxygen evolution reaction on perovskites," The Journal of Physical Chemistry Letters, vol. 9, no. 7, pp. 1473-1479, 2018.

[14] R. P. Forslund, W. G. Hardin, X. Rong et al., "Exceptional electrocatalytic oxygen evolution via tunable charge transfer interactions in $\mathrm{La}_{0.5} \mathrm{Sr}_{1.5} \mathrm{Ni}_{1-}{ }_{x} \mathrm{Fe}{ }_{x} \mathrm{O}_{4 \pm} \delta$ RuddlesdenPopper oxides," Nature Communications, vol. 9, no. 1, p. $3150,2018$.

[15] Z.-F. Huang, J. Song, Y. Du et al., "Chemical and structural origin of lattice oxygen oxidation in Co-Zn oxyhydroxide oxygen evolution electrocatalysts," Nature Energy, vol. 4, no. 4, pp. 329-338, 2019.

[16] J. T. Mefford, X. Rong, A. M. Abakumov et al., "Water electrolysis on $\mathrm{La}_{1-x} \mathrm{Sr}_{x} \mathrm{CoO}_{3-\delta}$ perovskite electrocatalysts," Nature Communications, vol. 7, no. 1, 2016.

[17] Y. Takeda, T. Hashino, H. Miyamoto, F. Kanamaru, S. Kume, and M. Koizumi, "Synthesis of $\mathrm{SrNiO}_{3}$ and related compound, $\mathrm{Sr}_{2} \mathrm{Ni}_{2} \mathrm{O}_{5}$," Journal of Inorganic and Nuclear Chemistry, vol. 34, no. 5, pp. 1599-1601, 1972.

[18] J. Guan, C. Li, J. Zhao et al., "FeOOH-enhanced bifunctionality in $\mathrm{Ni}_{3} \mathrm{~N}$ nanotube arrays for water splitting," Applied Catalysis B: Environmental, vol. 269, no. 1, article 118600, 2020.
[19] L.-F. Gu, J.-J. Chen, T. Zhou, X.-F. Lu, and G.-R. Li, "Engineering cobalt oxide by interfaces and pore architectures for enhanced electrocatalytic performance for overall water splitting," Nanoscale, vol. 12, no. 20, pp. 11201-11208, 2020.

[20] W. Zhou, J. Zhao, J. Guan, M. Wu, and G. R. Li, " $\mathrm{N}_{\mathrm{i} 3} \mathrm{~S}_{2}$ in Situ grown on Ni foam coupled with nitrogen-doped carbon nanotubes as an efficient electrocatalyst for the hydrogen evolution reaction in alkaline solution," ACS Omega, vol. 4, no. 23, pp. 20244-20251, 2019.

[21] W. Zhou, X.-F. Lu, J.-J. Chen et al., "Hierarchical porous prism arrays composed of hybrid $\mathrm{Ni}-\mathrm{NiO}-\mathrm{Carbon}$ as highly efficient electrocatalysts for overall water splitting," ACS Applied Materials \& Interfaces, vol. 10, no. 45, pp. 38906-38914, 2018.

[22] J.-X. Wu, C.-T. He, G.-R. Li, and J.-P. Zhang, "An inorganicMOF-inorganic approach to ultrathin $\mathrm{CuO}$ decorated $\mathrm{Cu}-\mathrm{C}$ hybrid nanorod arrays for an efficient oxygen evolution reaction," Journal of Materials Chemistry A, vol. 6, no. 39, pp. 19176-19181, 2018.

[23] A.-L. Wang, Y.-T. Dong, M. Li, C. Liang, and G.-R. Li, "In Situ derived $\mathrm{Ni}_{x} \mathrm{Fe}_{1-x} \mathrm{OOH} / \mathrm{NiFe} / \mathrm{Ni}_{x} \mathrm{Fe}_{1-x} \mathrm{OOH}$ nanotube arrays from NiFe alloys as efficient electrocatalysts for oxygen evolution," ACS Applied Materials \& Interfaces, vol. 9, no. 40, pp. 34954-34960, 2017.

[24] Y.-T. Dong, J.-X. Feng, and G.-R. Li, “Transition metal ioninduced high electrocatalytic performance of conducting polymer for oxygen and hydrogen evolution reactions," Macromolecular Chemistry and Physics, vol. 218, no. 22, article 1700359, 2017.

[25] A.-L. Wang, C.-L. Liang, X.-F. Lu, Y.-X. Tong, and G.-R. Li, "Pt- $\mathrm{MoO}_{3}-\mathrm{RGO}$ ternary hybrid hollow nanorod arrays as high-performance catalysts for methanol electrooxidation," Journal of Materials Chemistry A, vol. 4, no. 5, pp. 19231930, 2016.

[26] S.-H. Ye, J.-X. Feng, A.-L. Wang, H. Xu, and G.-R. Li, "Multilayered $\mathrm{Pt} / \mathrm{Ni}$ nanotube arrays with enhanced catalytic performance for methanol electrooxidation," Journal of Materials Chemistry A, vol. 3, no. 46, pp. 23201-23206, 2015.

[27] X.-F. Lu, A.-L. Wang, H. Xu, X.-J. He, Y.-X. Tong, and G.R. Li, "High-performance supercapacitors based on $\mathrm{MnO}_{2}$ tube-in-tube arrays," Journal of Materials Chemistry A, vol. 3, no. 32, pp. 16560-16566, 2015.

[28] H. Xu, L.-X. Ding, J.-X. Feng, and G.-R. Li, "Pt/Ni(OH) ${ }_{2}^{-}$ $\mathrm{NiOOH} / \mathrm{Pd}$ multi-walled hollow nanorod arrays as superior electrocatalysts for formic acid electrooxidation," Chemical Science, vol. 6, no. 12, pp. 6991-6998, 2015.

[29] X. Lu, G. Li, and Y. Tong, "A review of negative electrode materials for electrochemical supercapacitors," Science China-Technological Sciences, vol. 58, no. 11, pp. 1799-1808, 2015.

[30] L.-X. Ding, C.-L. Liang, H. Xu, A.-L. Wang, Y.-X. Tong, and G.-R. Li, "Porous hollow nanorod arrays composed of Alternating Pt and Pd nanocrystals with superior electrocatalytic activity and durability for methanol oxidation," Advanced Materials Interfaces, vol. 1, no. 3, article 1400005, 2014.

[31] H. Xu, L.-X. Ding, C.-L. Liang, Y.-X. Tong, and G.-R. Li, "High-performance polypyrrole functionalized PtPd electrocatalysts based on PtPd/PPy/PtPd three-layered nanotube arrays for the electrooxidation of small organic molecules," NPG Asia Materials, vol. 5, no. 11, article e69, p. e69, 2013.

[32] G.-R. Li, X.-H. Lu, C.-Y. Su, and Y.-X. Tong, "Facile synthesis of hierarchical $\mathrm{ZnO}: \mathrm{Tb}^{3+}$ nanorod bundles and their optical 
and magnetic properties," The Journal Physical Chemistry C, vol. 112, no. 8, pp. 2927-2933, 2008.

[33] G.-R. Li, X.-H. Lu, D.-L. Qu et al., "Electrochemical growth and control of $\mathrm{ZnO}$ dendritic structures," The Journal of Physical Chemistry C, vol. 111, no. 18, pp. 6678-6683, 2007.

[34] G.-R. Li, C.-R. Dawa, Q. Bu et al., "Electrochemical selfassembly of ZnO nanoporous structures," The Journal of Physical Chemistry C, vol. 111, no. 5, pp. 1919-1923, 2007.

[35] G.-R. Li, C.-R. Dawa, Q. Bu et al., "Electrochemical synthesis of orientation-ordered $\mathrm{ZnO}$ nanorod bundles," Electrochemistry Communications, vol. 9, no. 5, pp. 863-868, 2007.

[36] C. Yang, M. Batuk, Q. Jacquet et al., "Revealing pH-dependent activities and surface instabilities for Ni-based electrocatalysts during the oxygen evolution reaction," ACS Energy Letters, vol. 3, no. 12, pp. 2884-2890, 2018.

[37] C. Spöri, J. T. H. Kwan, A. Bonakdarpour, D. P. Wilkinson, and P. Strasser, "The stability challenges of oxygen evolving catalysts: towards a common fundamental understanding and mitigation of catalyst degradation," Angewandte Chemie International Edition, vol. 56, no. 22, pp. 5994-6021, 2017.

[38] M. Risch, A. Grimaud, K. J. May et al., "Structural changes of cobalt-based perovskites upon water oxidation investigated by EXAFS," The Journal of Physical Chemistry C, vol. 117, no. 17, pp. 8628-8635, 2013.

[39] D. Strmcnik, M. Uchimura, C. Wang et al., "Improving the hydrogen oxidation reaction rate by promotion of hydroxyl adsorption," Nature Chemistry, vol. 5, no. 4, pp. 300-306, 2013.

[40] R. Subbaraman, D. Tripkovic, K.-C. Chang et al., "Trends in activity for the water electrolyser reactions on $3 d \mathrm{M}(\mathrm{Ni}, \mathrm{Co},-$ Fe,Mn) hydr(oxy)oxide catalysts," Nature Materials, vol. 11, no. 6, pp. 550-557, 2012.

[41] R. Subbaraman, D. Tripkovic, D. Strmcnik et al., "Enhancing hydrogen evolution activity in water splitting by tailoring $\mathrm{Li}$ +-Ni (OH) 2 -Pt interfaces," Science, vol. 334, no. 6060, pp. 1256-1260, 2011.

[42] Y. Duan, S. Sun, Y. Sun et al., "Mastering surface reconstruction of metastable spinel oxides for better water oxidation," Advanced Materials, vol. 31, no. 12, article 1807898, 2019.

[43] Y. Zhu, G. Chen, Y. Zhong et al., “A surface-modified antiperovskite as an electrocatalyst for water oxidation," Nature Communications, vol. 9, no. 1, p. 2326, 2018.

[44] M. W. Louie and A. T. Bell, "An investigation of thin-film NiFe oxide catalysts for the electrochemical evolution of oxygen," Journal of the American Chemical Society, vol. 135, no. 33, pp. 12329-12337, 2013.

[45] I. D. Welsh and P. M. A. Sherwood, "Photoemission and electronic structure of $\mathrm{FeOOH}$ : distinguishing between oxide and oxyhydroxide," Physical Review B, vol. 40, no. 9, pp. 63866392, 1989.

[46] J. T. Mefford, W. G. Hardin, S. Dai, K. P. Johnston, and K. J. Stevenson, "Anion charge storage through oxygen intercalation in $\mathrm{LaMnO}_{3}$ perovskite pseudocapacitor electrodes," Nature Materials, vol. 13, no. 7, pp. 726-732, 2014.

[47] V. Tripkovic, H. A. Hansen, J. M. Garcia-Lastra, and T. Vegge, "Comparative DFT+U and HSE study of the oxygen evolution electrocatalysis on perovskite oxides," The Journal of Physical Chemistry C, vol. 122, no. 2, pp. 1135-1147, 2018.

[48] M. H. Seo, H. W. Park, D. U. Lee, M. G. Park, and Z. Chen, "Design of highly active perovskite oxides for oxygen evolution reaction by combining experimental and ab initio studies," ACS Catalysis, vol. 5, no. 7, pp. 4337-4344, 2015.

[49] S. C. Perry, D. Pangotra, L. Vieira et al., "Electrochemical synthesis of hydrogen peroxide from water and oxygen," Nature Reviews Chemistry, vol. 3, no. 7, pp. 442-458, 2019.

[50] J. R. Petrie, V. R. Cooper, J. W. Freeland et al., "Enhanced bifunctional oxygen catalysis in strained $\mathrm{LaNiO}_{3}$ perovskites," Journal of the American Chemical Society, vol. 138, no. 8, pp. 2488-2491, 2016.

[51] J. Bak, H. B. Bae, J. Kim, J. Oh, and S. Y. Chung, "Formation of two-dimensional homologous faults and oxygen electrocatalytic activities in a perovskite nickelate," Nano Letters, vol. 17, no. 5, pp. 3126-3132, 2017.

[52] L. C. Seitz, C. F. Dickens, K. Nishio et al., "A highly active and stable IrOx/SrIrO3catalyst for the oxygen evolution reaction," Science, vol. 353, no. 6303, pp. 1011-1014, 2016.

[53] B. Hülsen, M. Scheffler, and P. Kratzer, "Structural stability and magnetic and electronic properties ofCo2MnSi(001)/MgOHeterostructures: a density-functional theory study," Physical Review Letters, vol. 103, no. 4, article 046802, 2009.

[54] B. Han, A. Grimaud, L. Giordano et al., "Iron-based perovskites for catalyzing oxygen evolution reaction," The Journal of Physical Chemistry C, vol. 122, no. 15, pp. 8445-8454, 2018.

[55] N.-I. Kim, Y. J. Sa, T. S. Yoo et al., "Oxygen-deficient triple perovskites as highly active and durable bifunctional electrocatalysts for oxygen electrode reactions," Science Advances, vol. 4, no. 6, article eaap9360, 2018.

[56] A. Chen and J. Lipkowski, "Electrochemical and spectroscopic studies of hydroxide adsorption at the Au (111) electrode," The Journal of Physical Chemistry B, vol. 103, no. 4, pp. 682-691, 1999.

[57] T. Reier, Z. Pawolek, S. Cherevko et al., "Molecular insight in structure and activity of highly efficient, low-Ir Ir-Ni oxide catalysts for electrochemical water splitting (OER)," Journal of the American Chemical Society, vol. 137, no. 40, pp. 13031-13040, 2015.

[58] J. Greeley, I. E. L. Stephens, A. S. Bondarenko et al., “Alloys of platinum and early transition metals as oxygen reduction electrocatalysts," Nature Chemistry, vol. 1, no. 7, pp. 552-556, 2009.

[59] Y. S. Chu, T. E. Lister, W. G. Cullen, H. You, and Z. Nagy, "Commensurate water monolayer at the $\mathrm{RuO}_{2}$ (110)/water interface," Physical Review Letters, vol. 86, no. 15, pp. 33643367, 2001.

[60] T. T. Chen and R. K. Chang, "Surface enhanced raman scattering of interfacial DOD, HOD, and $\mathrm{OD}^{-}$," Surface Science, vol. 158, no. 1-3, pp. 325-332, 1985.

[61] R. L. Frost, M. L. Weier, and J. T. Kloprogge, "Raman spectroscopy of some natural hydrotalcites with sulphate and carbonate in the interlayer," Journal of Raman Spectroscopy, vol. 34, no. 10, pp. 760-768, 2003.

[62] S. Speziale, R. Jeanloz, A. Milner, M. P. Pasternak, and J. M. Zaug, "Vibrational spectroscopy ofFe $(\mathrm{OH}) 2$ at high pressure: behavior of the O-H bond," Physical Review B, vol. 71, no. 18, article 184106, 2005.

[63] M. C. Bernard, P. Bernard, M. Keddam, S. Senyarich, and H. Takenouti, "Characterisation of new nickel hydroxides during the transformation of $\alpha \mathrm{Ni}(\mathrm{OH})_{2}$ to $\beta \mathrm{Ni}(\mathrm{OH})_{2}$ by ageing," Electrochimica Acta, vol. 41, no. 1, pp. 91-93, 1996.

[64] J. Desilvestro, D. A. Corrigan, and M. J. Weaver, "Spectroelectrochemistry of thin nickel hydroxide films on gold using 
surface-enhanced Raman spectroscopy," The Journal of Physical Chemistry, vol. 90, no. 24, pp. 6408-6411, 1986.

[65] N. Chaban, M. Weber, S. Pignard, and J. Kreisel, "Phonon Raman scattering of perovskite $\mathrm{LaNiO}_{3}$ thin films," Applied Physics Letters, vol. 97, no. 3, article 031915, 2010.

[66] M. A. Peña and J. L. G. Fierro, "Chemical structures and performance of perovskite oxides," Chemical Reviews, vol. 101, no. 7, pp. 1981-2018, 2001.

[67] Y. Tong, J. Wu, P. Chen et al., "Vibronic superexchange in double perovskite electrocatalyst for efficient electrocatalytic oxygen evolution," Journal of the American Chemical Society, vol. 140, no. 36, pp. 11165-11169, 2018.

[68] L. Giordano, B. Han, M. Risch et al., "pH dependence of OER activity of oxides: current and future perspectives," Catalysis Today, vol. 262, pp. 2-10, 2016.

[69] K. Juodkazis, J. Juodkazyte,, R. Vilkauskaitè, and V. Jasulaitienè, "Nickel surface anodic oxidation and electrocatalysis of oxygen evolution," Journal of Solid State Electrochemistry, vol. 12, no. 11, pp. 1469-1479, 2008.

[70] J. O. M. Bockris and T. Otagawa, "Mechanism of oxygen evolution on perovskites," The Journal of Physical Chemistry, vol. 87, no. 15, pp. 2960-2971, 2002.

[71] C. C. L. McCrory, S. Jung, J. C. Peters, and T. F. Jaramillo, "Benchmarking heterogeneous electrocatalysts for the oxygen evolution reaction," Journal of the American Chemical Society, vol. 135, no. 45, pp. 16977-16987, 2013.

[72] W. Zhou and J. Sunarso, "Enhancing bi-functional electrocatalytic activity of perovskite by temperature shock: a case study of $\mathrm{LaNiO}_{3-\delta}$," The Journal of Physical Chemistry Letters, vol. 4, no. 17, pp. 2982-2988, 2013.

[73] C. Gong, L. Zhao, S. Li et al., "Atomic layered deposition iron oxide on perovskite $\mathrm{LaNiO}_{3}$ as an efficient and robust bifunctional catalyst for lithium oxygen batteries," Electrochimica Acta, vol. 281, pp. 338-347, 2018.

[74] J. Q. Adolphsen, B. R. Sudireddy, V. Gil, and C. Chatzichristodoulou, "Oxygen evolution activity and chemical stability of $\mathrm{Ni}$ and Fe based perovskites in alkaline media," Journal of the Electrochemical Society, vol. 165, no. 10, pp. F827-F835, 2018.

[75] Z. Zhang, B. He, L. Chen et al., "Boosting overall water splitting via $\mathrm{FeOOH}$ nanoflake-decorated PrBa0.5Sr0.5Co2O5 $+\delta$ Nanorods," ACS Applied Materials \& Interfaces, vol. 10, no. 44, pp. 38032-38041, 2018.

[76] G. Chen, Y. Zhu, H. M. Chen et al., "An amorphous nickeliron-based electrocatalyst with unusual local structures for ultrafast oxygen evolution reaction," Advanced Materials, vol. 31, no. 28, article 1900883, 2019.

[77] D. A. Kuznetsov, B. Han, Y. Yu et al., "Tuning redox transitions via inductive effect in metal oxides and complexes, and implications in oxygen electrocatalysis," Joule, vol. 2, no. 2, pp. 225-244, 2018.

[78] H. Wang, J. Wang, Y. Pi, Q. Shao, Y. Tan, and X. Huang, "Double perovskite $\mathrm{LaFe}_{x} \mathrm{Ni}_{1}-\mathrm{xO}_{3}$ Nanorods enable efficient oxygen evolution electrocatalysis," Angewandte Chemie International Edition, vol. 58, no. 8, pp. 2316-2320, 2019.

[79] D. Zhang, Y. Song, Z. Du, L. Wang, Y. Li, and J. B. Goodenough, "Active $\mathrm{LaNi}_{1-x} \mathrm{Fe}_{x} \mathrm{O}_{3}$ bifunctional catalysts for air cathodes in alkaline media," Journal of Materials Chemistry A, vol. 3, no. 18, pp. 9421-9426, 2015.

[80] J. Rodriguez-Carvajal, Satellite meeting on powder diffraction of the XV congress of the IUCr, Toulouse, France, 1990.
[81] A. Y. Dobin, K. R. Nikolaev, I. N. Krivorotov, R. M. Wentzcovitch, E. D. Dahlberg, and A. M. Goldman, "Electronic and crystal structure of fully strainedLaNiO3films," Physical Review B, vol. 68, no. 11, article 113408, 2003.

[82] P. Giannozzi, S. Baroni, N. Bonini et al., "Quantum Espresso: a modular and open-source software project for quantum simulations of materials," Journal of Physics: Condensed Matter, vol. 21, no. 39, article 395502, 2009.

[83] J. P. Perdew, K. Burke, and M. Ernzerhof, "Generalized gradient approximation made simple," Physical Review Letters, vol. 77, no. 18, pp. 3865-3868, 1996.

[84] M. Cococcioni and S. De Gironcoli, "Linear response approach to the calculation of the effective interaction parameters in theLDA+Umethod," Physical Review B, vol. 71, no. 3, article 035105, 2005. 